NBER WORKING PAPER SERIES

\title{
EQUITY STYLE RETURNS AND INSTITUTIONAL INVESTOR FLOWS
}

\author{
Kenneth A. Froot \\ Melvyn Teo \\ Working Paper 10355 \\ http://www.nber.org/papers/w10355
NATIONAL BUREAU OF ECONOMIC RESEARCH
1050 Massachusetts Avenue
Cambridge, MA 02138
March 2004

We thank State Street Corporation, Atindra Barua, and Jessica Lo for help with the data, Harvard Business School Division of Research for financial support, and Jeremy Armitage, Paul O'Connell, Tarun Ramadorai, and Andrei Shleifer for many helpful comments and suggestions. The views expressed herein are those of the authors and not necessarily those of the National Bureau of Economic Research.

(C)2004 by Kenneth A. Froot and Melvyn Teo. All rights reserved. Short sections of text, not to exceed two paragraphs, may be quoted without explicit permission provided that full credit, including (C notice, is given to the source. 
Equity Style Returns and Institutional Investor Flows

Kenneth A. Froot and Melvyn Teo

NBER Working Paper No. 10355

March 2004

JEL No. G12, G14

\section{$\underline{\text { ABSTRACT }}$}

This paper explores institutional investor trades in stocks grouped by style and the relationship of these trades with equity market returns. It aggregates transactions drawn from a large universe of approximately $\$ 6$ trillion of institutional funds. To analyze style behavior, we assign equities to deciles in each of five style dimensions: size, value/growth, cyclical/defensive, sector, and country. We find, first, strong evidence that investors organize and trade stocks across style-driven lines. This appears true for groupings both strongly and weakly related to fundamentals (e.g., industry or country groupings versus size or value/growth deciles). Second, the positive linkage between flows and returns emerges at daily frequencies, yet becomes even more important at lower frequencies. We show that quarterly decile flows and returns are even more strongly positively correlated than are daily flows and returns. However, as the horizon increases beyond a year, we find that the flow/return correlation declines. Third, style flows and returns are important components of individual stock expected returns. We find that nearby style inflows and returns positively forecast future returns while distant style inflows and returns forecast negatively. Fourth, we find strong correlations between style flows and temporary components of return. This suggests that behavioral theories may play a role in explaining the popularity and price impact of flow-related trading.

Kenneth A. Froot

Harvard Business School

Morgan 391

Boston, MA 02163

and NBER

kfroot@hbs.edu
Melvyn Teo

Singapore Management University

School of Business

469 Bukit Timah Road

Business Building

\#03-36 Singapore 259756

melvynteo@smu.edu.sg 
Investors use concepts of investment styles to characterize their portfolios and patterns of trade. Popular styles (e.g., technology stocks, growth stocks, cyclical stocks, etc.) are widely followed both because they help summarize what happened in the marketplace, and because they represent factors across which investors attempt to diversify. Investment fund mandates often explicitly designate style exposures. These pools are then used for asset allocation by principal investors and agents responsible for asset allocation. Judging from its popularity in common parlance and the press, style rotation should be an important source of trading for many investors as mandates change or as principals reallocate their portfolios.

Two natural questions to ask about style trading are whether institutional investors do indeed trade on the basis of commonly used style concepts, and, if so, whether such style-driven trading affects prices. Clearly, in a classical finance world, investors would group and trade assets in style categories if and only if the style categories were related to underlying fundamentals. For example, if firm size was related to underlying exposure to some fundamental factor then size might appear as a factor that explains investor reallocation.

Alternatively, if an investor group experiences non-fundamental sentiment shocks organized around style, then stocks with common (dissimilar) styles should experience common (dissimilar) shocks. Naturally, these demand shocks will translate into trading by investors affected by these shocks. Relative to fundamentals, nearby style segment returns will exhibit excess comovement, while distant style segment returns will exhibit insufficient comovement. Moreover, if the demands are not based on intrinsic sources of value, these excess or insufficient price comovements will disappear at long horizons.

In addition, if style-based investors are also positive feedback traders then they buy into styles that performed well in the past. This generates style-related momentum at relatively short horizons. If rational investors are present and exploit this behavior, style reversals also emerge. Note that these style-level continuations and reversals are distinct from their stock-level counterparts (see Barberis and Shleifer, 2003).

The empirical implications of a style investing story have been traced out across a number of fronts. Harvdouvelis, La Porta, and Wizman (1994) find that closed-end country funds in the U.S. move too much with the U.S. market relative to their NAVs. 
Barberis, Shleifer, and Wurgler (2003) show that stocks entering (leaving) major indexes witness increases (decreases) in comovement with the index. Froot and Dabora (1999) study "Siamese twin" firms (like Royal Dutch and Shell), which share cash flows but are traded in different locations by different clienteles. Their prices comove too little with each other but too much with the market of their main clientele. Moskowitz and Grinblatt (1999) and Asness, Liew, and Stevens (1997) successfully apply momentum and reversal strategies to industry portfolios and country portfolios respectively. Lewellen (2002) finds that momentum strategies using size and book-to-market portfolios are at least as profitable as individual stock momentum. Chen and De Bondt (2003) uncover evidence of style momentum within the S\&P 500 index. Teo and Woo (2003) document strong evidence of style level reversals for stocks grouped into value/growth and small/large styles at annual horizons.

This paper is an investigation of the empirical importance of style in institutional trading patterns and returns. We examine five exhaustive style dimensions, four of which are alternative sorts of purely US stocks. The four dimensions are small/large, value/growth, cyclical/defensive, and sector/industry. We also examine an international style dimension using returns and flows across countries. To do all this, we pair daily returns with high-resolution information on aggregated institutional investor flows from State Street Corporation, based on their custody assets of about $\$ 6$ trillion. We ask: how important are these style designations for trading patterns?; Is the evidence robust to changes in the definition of style categories?; How do these style segments interact with style-related prices?; and, are returns of and flows into style segments important for understanding the returns of and flows into individual stocks?

Our paper builds on and differs from the above-mentioned studies on style momentum and style reversals in several ways. The simultaneous examination of different style dimensions allows us to compare and contrast style effects across various style categories. For example, Cavaglia, Brightman, and Aked (2000) suggest that the importance of country style has diminished relative to that of the sector/industry style. Our multi-dimensional style classification allows for a test of this. Further, the high frequency institutional flow data lets us examine short-term style momentum. This is particularly interesting as Teo and Woo (2003) suggest that style momentum occurs at 
frequencies of less than a quarter. The inclusion of stock flows, stock returns, and stock characteristics in our controls allows us to abstract away from stock-level stories of return predictability and to establish the style-level explanation.

We find that there is strong evidence that institutional investors organize and trade stocks according to style. This is true for four of the five styles that we examine. The fifth -- our measure of cyclical/defensive segments -- does not seem to isolate unusual trading patterns among professional investors. We also find that size, value/growth, and industry/sector styles have increased importance over time relative to a country/region style.

We also find a positive relationship between style flow and style returns at daily frequencies. This relationship becomes even more positive as horizons are stretched to a quarter, where positive, noncontemporaneous correlations become important. However, at frequencies of a year or more, negative noncontemporaneous correlations take over. Related to this, we find that at horizons less than a quarter, own-style segment returns and flows forecast stock returns positively. But at horizons of a quarter and beyond, ownstyle segment returns and flows forecast stock returns negatively. As would be expected under the sentiment story, this relationship is reversed with distant style segments flows and returns.

These results fit closely with those of Froot and Ramadorai (2003) who investigate the relationship between currency returns and flows. They, like us, find evidence that flows are strongly related to temporary return components. This is a crucial empirical prediction of the style-investing story of Barberis and Shleifer (2003). They show that the interaction between positive feedback style switchers and rational arbitrageurs induces style-level continuations at short horizons and reversals at longer horizons. Our findings also complement those of Teo and Woo (2003) and Kumar (2002). Teo and Woo (2003) fail to find strong evidence of momentum at quarterly horizons because style momentum occurs at weekly and monthly horizons and moves toward reversal at quarterly horizons. Kumar (2002) uses retail investor data to examine the interaction of style-switching and relative style returns. He finds positive evidence of style-driven trading, though he does not investigate implications at the individual stock level. 
It is also interesting to relate our findings to the extant literature on institutional investors. Grinblatt, Titman, and Wermers (1995), Daniel, Grinblatt, Titman, and Wermers (1997), Carhart (1997), Nofsinger and Sias (1999), and Grinblatt and Keloharju (2000), find that institutional investors tend to be positive feedback or momentum traders, in that they tend to buy stocks that performed well in the past. Our study extends this result by showing that institutional investors are also momentum traders at the style level. That is, they buy into groups of stocks that have performed well in the past even if some of the stocks have not individually performed well.

Nofsinger and Sias (1999) and Froot, O'Connell, and Seasholes (2001) find evidence that flows into U.S. and international stocks are positively correlated with future own-country returns. We document a similar anticipation effect at the style level. Size, value/growth, and sector segments which experience strong flows show future positively correlated returns. Furthermore, we find that these style-level anticipation effects are distinct from anticipation at the stock level. Gompers and Metrick (2000) report that institutional investors display an unconditional preference for large stocks. Our size results qualify this statement by showing that institutional investors have relatively stronger preferences for large stocks when recent large-stock returns have been high relative to small-stock returns.

The remainder of the paper is organized as follows. Section I describes the data. Section II examines the results in 5 subsections. There, we investigate: the reallocation propensities across style segments for different style classifications; the contemporaneous correlations between style returns and flows across different time horizons; the noncontemporaneous relationship between style returns and flows; the impact of past style returns and flows on stock returns; and the dynamic flow/return relationship framed as a vector autoregression. Section III concludes and suggests avenues for further research.

\section{Data and Definitions of Styles}

We track the investment flows of a group of large, institutional investors, with approximately $\$ 8$ trillion in assets. The data are from State Street Corporation (henceforth SSC), and represent complete accounts of all equity transactions for all 
included portfolios. SSC is the largest US master trust custodian bank, the largest US mutual fund custodian (with nearly $40 \%$ of the industry's funds under custody), and the world's second largest custodian. It has approximately $\$ 8$ trillion in institutional assets under custody. SSC records all transactions for these assets. The data are filtered to remove test and error transactions, and transactions which contain missing data fields. While SSC records all information at the trade level we aggregate the purchases and sales each day to calculate the daily net inflows - the difference between dollar purchases and dollar sales -into each stock. This high-resolution flow database represents a substantial improvement over that used in Froot, O'Connell, and Seasholes (2001) in several respects: trades are recorded on a trade-date rather than on a settlement-date basis; trades are grouped by stock rather than by currency of settlement (which Froot, O'Connell, and Seasholes used as a proxy for the firm's country of incorporation). Futures and structured notes are not included, although some derivatives, such as ADRs are included in the data. The sample period runs from January 3, 1995 to December 31, 2001. For this study we focus primarily on flows in US equities, though for some purposes we include information on global equities as well. ${ }^{1}$ Table I provides some summary statistics from the US flow database broken down year by year. The consistently large number of stocks spanned by the database and the high trading volumes suggest that the flow database captures a sizeable portion of all trades in the US.

The US equity returns and stock characteristic data are from the Center for Research in Security Prices at the University of Chicago (CRSP) and COMPUTSTAT. Our analysis covers all stocks traded on the NYSE, AMEX, and NASDAQ that are ordinary common shares, excluding ADRs, SBIs, certificates, unit trusts, REITs, closedend funds, companies incorporated outside the US, and Americus Trusts.

We work with several style dimensions - small/large capitalization, value/growth, cyclical/defensive, sector, and global region. The first four of these apply to US stocks only. The last applies to global stocks. Within each style dimension, we organize stocks into deciles. Decile returns are calculated using a capitalization-weighted average; decile

\footnotetext{
${ }^{1}$ Notwithstanding the higher quality of the data, we ameliorate the effects of a small percentage of outliers, which we define as daily stock flow observations where absolute net inflows are greater than 10 percent of the stock market capitalization.
} 
flows are the sum of constituent-stock dollar flows divided by decile total market capitalization.

Each stock is assigned to a style decile based on its prior year characteristics. The details vary slightly across style dimensions. For the size dimension, deciles for each are assigned as of July $1^{\text {st }}$ based on the immediately prior June $30^{\text {th }}$ market equity capitalization. The assignment remains for the subsequent year through June 30, at which point the stock is similarly reassigned based on capitalization at that time. We compute each decile's return as the mean value-weighted return of all the stocks in the decile. Breakpoints for size deciles are determined based on equal-capitalization size

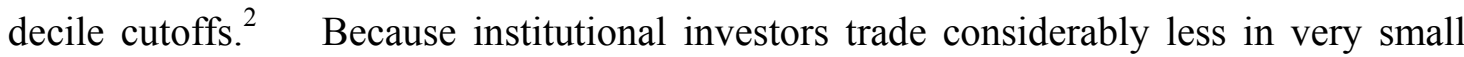
stocks deciles are more accurately measured using on equal capitalization than using equal numbers of firms.

To calculate value/growth deciles, we sort based on firms' book-to-market equity (BE/ME) values each July $1^{\text {st }}$ of year $t$ through June 30 of year $t+1$. The information used is book equity in the fiscal year ending in calendar year $t-1$ and market capitalization in December of year $t-1$. Following Fama and French (1992), the timing conventions both size and $\mathrm{BE} / \mathrm{ME}$ ensure that accounting variables are known before the sort. Breakpoints for $\mathrm{BE} / \mathrm{ME}$ are based on equal-capitalization decile cutoffs. They correspond closely to Fama and French (1993) NYSE BE/ME breakpoints. ${ }^{3}$

To calculate sector groups, we sort into sector deciles based on firm SIC codes as of June $30^{\text {th }}$ in year $t$ using the Fama and French (1997) 10 industry portfolio classification. Firms remain in that sector group until June $30^{\text {th }}$ of year $t+1$, when the procedure is repeated.

Many professional investors say they group stocks according to their sensitivity to the business cycle. We call this style dimension cyclical/defensive. To calculate cyclical/defensive deciles, we sort stocks based on the correlation between stock return this quarter and US GNP growth one year forward where one year forward includes the current quarter and the subsequent three quarters. We do this each year in July in a

\footnotetext{
${ }^{2}$ Because our sample includes AMEX and NASDAQ stocks, we do not follow Fama and French (1993) who use NYSE size breakpoints to determine the decile cutoffs.

${ }^{3}$ We note that our results are very similar when we use NYSE ME and BE/ME breakpoints to partition stocks into $\mathrm{ME}$ and $\mathrm{BE} / \mathrm{ME}$ deciles respectively.
} 
backward looking way, based on previously observed values of GNP growth and return. Because GNP data are only quarterly, for each year the correlations are computed only for stocks that have a minimum of 5 years of history at that time. Each year, we then assign stocks to equal-capitalization deciles based on the previous GNP/return correlation measured over the last 5 years.

To form regional groupings of firms, we use a stock's country of incorporation. We include stocks from 50 countries. For most of our analysis, we group these countries into 10 exhaustive and mutually exclusive regions: US, Canada, Developed Europe (including Euro, excluding United Kingdom), United Kingdom, Japan, Australia/New Zealand, Emerging Europe, Emerging Asia, Emerging Latin America, and Emerging Others.

As in other cases, country/region flows are just dollar flows scaled by their respective market capitalization (here we use MSCI total country market capitalization). In aggregating the data to the country/region level, we truncate aggregate daily flows using two filters. The first truncates daily country flow observations in excess of $5 \%$ of the country market capitalization and the second truncates flows that are more than 5 standard deviations from the mean. We do not omit extreme country flows due to the limited number of cross-sectional observations. Also, the stricter truncation rules in the country case reflect the fact that country flows are more aggregated than stock flows and hence should be better behaved. Country returns are from Datastream country price indices, while region returns are value-weighted average returns of all constituent countries. 


\section{Empirical results}

\section{A. Styles and trading behavior: Reallocation propensities across style segments}

If styles are important to the way that investors group stocks, then style-based trading should be relatively more important than other, random sources of trading. Trading associated with styles could of course be related to fundamentals. However, if there is some relation, it is unlikely to be a simple one. Since our flows measure the reallocation toward large institutional investors and away from other investors, a directional change in fundamentals is unlikely to consistently result in a reallocation toward or away from institutional investors. Froot and Ramadorai (2003) examine currency flows in the context of a model of exchange-rate value, and find that there is little relationship between flows and important fundamentals. However, they do find an important positive relationship between flows and returns, suggesting that institutional investors' demands push prices.

Of course, style-based trading may be in part or completely driven by investor sentiment and noise, rather than fundamentals. This is more likely to be the case for style dimensions that have less of an obvious relationship with fundamentals, such as size. Country, sector, and cyclical/defensive designations are more likely to spring more from an organization scheme based on fundamentals. For the size dimension, however, it may be harder to argue that fundamentals are at the root of the attention given to differences in firm size.

In order to gauge the importance of style designations and how they vary over time, we wish to measure the extent to which they explain trading behavior. The first step in doing so is to construct measures sensitive to reallocation intensity. How much do investors move money from small-cap to large-cap, or from value to growth, or from manufacturing stocks to utilities? How much do investors move money across arbitrary groupings of stocks? A measure of their re-allocation intensities across different style categorizations should give a rough indication of the relative importance institutional investors place on different categorizations compared with arbitrary categorizations. 
We use a "reallocation intensity" statistic for computing trading across different styles and arbitrary classifications. We define re-allocation intensity as the cross-decile standard deviation of demeaned excess flow over and above expected flow based on segment market capitalization:

$$
\sigma_{t}^{f} \equiv\left(\left(\frac{1}{10}\right) \sum_{i=1}^{10}\left(F_{i, t}-m_{i, t}\left(\frac{\sum_{i} F_{i, t}}{\sum_{i} m_{i, t}}\right)\right)^{2}\right)^{0.5}
$$

where $F_{i, t}$ is the dollar flow into segment $i$ at time $t$ while $m_{i, t}$ is the market capitalization of segment $i$ at time $t$. Excess flows in each segment $i$ are defined as the flows into segment $i$ less the expected flow based on segment market capitalization and the amount of total market capitalization purchased by institutions that day, $F_{i, t}-m_{i, t}\left(\sum_{i} F_{i, t}\right) /\left(\sum_{i} m_{i, t}\right)$.

A comparison of reallocation intensities across styles of stocks will give us a feel for the relative importance of different style dimensions to institutional investors. In addition, we can gain a sense of the absolute importance of style categorizations by comparing style reallocation intensities with reallocation intensities when stock deciles are arbitrarily determined.

It is possible to evaluate what we can learn incrementally from using flow data. To do so, we calculate cross-sectional standard deviations of returns for different categorizations. Much of the work below suggests that style returns are positively correlated with style flows (suggesting that institutional investors, on average, take, rather than provide, liquidity). As a result, one might expect to find that those styles with greater reallocation intensities are also those with the greater cross-sectional return variation. Of course, returns also contain components that are unrelated to flows. For example, the public release of information may often result in price changes, but not changes in the relative preferences of institutional versus other investors. Thus we might expect cross-sectional return variation to be an imperfect proxy for cross-sectional reallocation intensity. 
The cross-sectional standard deviations of weekly returns plotted in Figure 1 (top panel) give rise to several broad observations. First, during our sample period crosssectional return volatility increases on average for all but the regional style dimension. The appearance of a trend may be attributable to the low levels of index volatility in 1995 and the very high levels in the stock market boom and bust through 2002. The dispersions of returns for the various domestic equity classifications are positively correlated and increase over the 6-year sample period by a factor of about two. Furthermore, one can identify positive shocks that commonly affect all series, such as the Russia/LTCM shock in the fall of 1998, and the 'echo-crash' shock in the fall of 1997.

Second, cross-sectional volatility of regional returns has fallen relative to the volatility for sector, value/growth, and size categorizations. Before 1999, returns across country segments were the most volatile, with volatility peaking at the time of the Russia/LTCM crisis. By contrast, after 1999, return volatility across sector segments was greatest. These findings echo those of Cavaglia, Brightman, and Aked (2000) who find that sectors have become more important relative to the countries in driving crosssectional return volatility in recent years.

Third, within the US market only, cross-sectional return volatility across sectors has consistently been $30 \%-40 \%$ above comparable volatilities for other style dimensions. The exception was in 2001, during the collapse of the NASDAQ bubble, when value/growth return volatility rose above sector volatility. Recently, value/growth volatility has plummeted below that of size, with cyclical/defensive volatility moving ahead of both.

The reallocation intensities plotted in the bottom panel of Figure 1 use flows to calculate a similar volatility statistic, given in equation (1). Several points are important. First, as with return volatility, there is a mild upward trend in the trading intensity of institutional investors in US stocks (size, value/growth, sector, and cyclical/defensive). Second, there is visual evidence of a strong common factor in these US styles. This common factor is evident even in randomly generated US deciles. It is, however, not strongly shared with global reallocation intensities, which did not increase at the time that stock prices began to fall in 2000. Third, the importance of country reallocation has clearly fallen relative reallocation within the US market (i.e., sectors, size, value/growth 
and cyclical/defensive). Investors traded relatively more intensively across country segments prior 2000 .

Figure 1 provides no information on statistical significance. To remedy this, we employ a simple Monte Carlo to determine, for each week, a benchmark level of reallocation intensity. The benchmark we use is the median reallocation intensity across 1,000 draws in which all contemporaneously useable stocks are randomly assigned to 10 deciles whose market capitalizations match those of the style segments. We do this independently for each day, and then formally test whether the reallocation intensity for a given style dimension is statistically above the median, using a simple $t$-statistic across days.

Table II reports the results of these $t$-tests, performed for each year of the sample and for the entire sample, for each of the four domestic-stock style dimensions. ${ }^{4}$ The results suggest that trading patterns seem strongest in sector, then size and value/growth, then considerably lower, cyclical/defensive. All styles are traded statistically more than random groupings of stocks. The importance of style-based trading has grown; all styles save one reach their highest level of significance in the last year of our sample, 2001. Indeed, style-based trading has grown since 1999 even as prices and trading volumes have fallen. Moreover, style-based trading is strong enough to be detectable in just over a year, as is evident from the statistically significant annual reallocation intensities for the size, value/growth, and sector style spectrums.

Clearly the trading patterns across the cyclical/defensive segments are significantly weaker than those for the other style spectrums. None of the year by year reallocation intensities for cyclical/defensive are statistically greater than their random counterparts. One reason for this may be that, while cyclical/defensive is important, investors are more forward looking than currently modeled with the backward-looking cyclical/defensive measure. That is they correctly guess the ability of stocks to forecast GNP, and group stocks according to this forward-looking measure. This measure in turn drives a lot of trading along these lines. To check this intuition, we compute a forwardlooking cyclical/defensive measure that uses the correlation between stock returns over

\footnotetext{
${ }^{4}$ These $t$-tests are performed by stacking the daily cross-sections over the entire subsample, and treating the stack as a large cross-section.
} 
the sample period and one year forward GNP growth. Next, we perform a similar exercise with the reallocation intensities across the forward-looking cyclical/defensive deciles. The results in Table II suggest that a forward-looking measure, which could perhaps be proxied with various non-observables, drives much of investor reallocation. The year by year reallocation intensities for the forward looking cyclical/defensive measure are almost always statistically different from the monte carlo $50^{\text {th }}$ percentile. Nonetheless, for the rest of the paper, we shall continue to use the backward-looking cyclical/defensive measure for consistency with the backward-looking nature of our market equity and book-to-market derivations.

One interpretation of the overall evidence in Figure 1 and Table II is that the cross-sectional volatility of US fundamentals increased over time and relative to the volatility of international fundamentals. However, this interpretation may not apply that well to value/growth and size styles. These styles are likely to be less well differentiated by fundamentals than by investor convention.

A second interpretation is that there has been little change in fundamental variation between value versus growth or small versus large cap firms, but considerable change in the ability of investors to efficiently allocate their portfolio across these style dimensions. Mutual funds, ETFs, and other basket mandates expedite these changes in exposure. These mandates have become increasing specific and precisely targeted as well. International reallocation has for a much longer period of time been facilitated by funds and basket products. So it is not surprising that while that international reallocation intensity has not fallen in absolute terms, it has declined relative to domestic styles.

\section{B. Characteristics-based reallocation across style segments}

In the previous section, we find that institutional investors consistently reallocate their funds across style segments, and that they do so with an intensity greater than expected based on randomly-generated segments. This finding is interesting, but only of limited value. It is limited because it does not clarify the pattern of reallocation across deciles. For example, we would observe high trading intensity in a given dimension if investors tend to buy deciles 1,5 , and 10 simultaneously, selling deciles 2-4 and 6-9 to do 
so. However, this pattern of reallocation doesn't really fit with our idea of a "size" spectrum. It suggests investors key off different or more complex factors than simply size. By contrast, if we find that investors buy deciles 1 and 2 simultaneously, selling deciles 9 and 10 to do so, size does well as a means of explaining reallocations.

If "size" does well in explaining that pattern of flows across size deciles it could be because size is correlated with exposure to some underlying fundamental shock or preference shock. Models of the former would include Brennan and Cao (1997), who model far-away investors as having less precise information than nearby investors. As a consequence, far-away investors rationally update their prior beliefs by more than nearby investors, and therefore tend to buy in response to publicly announced fundamental news. Institutional investors, may, for example be "farther" from small company stocks and "nearer" large company stocks. Size-related flows could then be driven by fundamentals.

Alternatively, size may be correlated with exposure to a preference shock. In Barberis and Shleifer (2003) a group of investors key off the relative returns of extremestyle stocks, thereby grouping them together, even when there is no fundamental motivation for doing so. "Size" is a style because investors follow it, not because it reflects relative fundamental risk exposures.

If the styles we examine are driven by a single common factor, those investing in, say, the large cap segment would be simultaneously selling the small cap segment. That is, we would observe switching across segments which is more pronounced between more distant segments. In this subsection we investigate and test whether the correlation of flows between style segments is lower for more distant deciles.

To examine this we first plot the 12 week moving average of excess flow for the extreme size and value/growth deciles in Figure 2, where excess flow into decile $i$ is defined as $F_{i, t}-m_{i, t}\left(\sum_{i} F_{i, t}\right) /\left(\sum_{i} m_{i, t}\right)$. From Figure 2, we clearly see a strong negative correlation between excess flows into the most distant deciles - i.e., small (ME1) versus large (ME10), and growth (BM1) versus value (BM10). Further, this negative correlation is evident throughout the entire 6 year sample. To confirm this we compute pairwise correlations between weekly excess ME1 and ME10 flow and between weekly excess BM1 and BM10 flow, as well as their associated t-statistics. The results in Table III 
validate our initial observations. The correlation coefficient between small and large excess flow is -0.44 , that between value and growth excess flow is -0.34 , and that between the most cyclical and the most defensive deciles is -0.18 . The first two are statistically different not only from zero, but also from -0.11 , the negative correlation expected ex ante among randomized deciles of firms' excess flows. The correlation between cyclical and defensive is not statistically different from -0.11 however.

Clearly, the single factor argument can be taken further. If there is a single factor driving reallocation across a given style, then nearby styles should be less negatively correlated (and may even be positively correlated) while distant styles should be strongly negatively correlated. We therefore look for evidence of a gradual decrease in pairwise correlations as the distance between style segments increases, computing pairwise correlations for all pairs of size, value/growth, and cyclical/defensive segments. Table III reports pairwise correlation coefficients averaged across equally-distant pairs (distance is defined here as the difference in rank between the pair, i.e., the distance between deciles 2 and 8 is 6$)$.

The results in Table III provide strong evidence that investors use characteristics similar to value/growth, small/large, and cyclical/defensive in determining trading behavior. Reallocation across deciles is broadly monotonic in book-to-market (value/growth), and market capitalization (size). Specifically, the correlation between deciles decreases almost monotonically as the distance between them increases. For instance, the correlation between ME1 and ME2 is statistically positive at 0.26. This decreases to -0.08 for the pair ME1 and ME5 and decreases further to -0.44 for the pair ME1 and ME10. The $t$-statistics in Table III are against the null hypothesis that the excess flows are random across deciles; under the null, these correlations are all -0.11.

The effect is not confined to pairs that include an extreme decile. Table III shows that the average correlation coefficient for all segments $x$ deciles apart declines as the absolute value of $x$ rises. We also compute Spearman rank correlations to test formally this result against the null hypothesis that the correlation coefficients and distance measures are unrelated. We easily reject this null hypothesis for the size and value/growth styles. 
Principle components analysis is another means of determining whether a single or small number of factors drive a given style's flows. We form the most important principal components of each style's flows and then report the fraction of variation of segment flows that are explained by those components. We then test whether this $R^{2}$ is statistically greater than that found in randomly aggregated deciles. The results for the top five principal components (sorted by their eigenvalues) are displayed in Table IV. The reported numbers are the $R$-squares signed by the sign of the regression coefficient estimates to give a better picture of the correlations between the principal components and the segment flows.

The results from Table IV suggest that a large portion of inter-decile reallocation fits with sensible notions of style reallocation: the most extreme deciles have opposite exposures to the most important principle components, while near-extreme deciles have similarly-signed exposures to the nearby extreme. For example, the main principal component for size segment flow loads positively on the large style segments (ME8ME10) and negatively on the small style segments (ME1-ME3), acting as a proxy for style-switching activity along the size spectrum. Similarly the most extreme deciles have strongly opposite exposures to the second-largest principle component. The first and second principal components explain $23.0 \%$ and $17.7 \%$, respectively, of the crosssectional variation in returns. The results are similar for the value/growth and cyclical/defensive styles.

If the deciles were comprised of randomly-assigned firms, we would not expect these results. The randomly-generated deciles of existing firms from the Monte Carlo yield an average exposure of zero, and suggest that the first and second principle components contribute on average 20.5 and $16.0 \%$ of variation in cross-decile reallocation. These $R^{2}$ levels are below those estimated for our value/growth and size style dimensions.

Summing up, the results in the section provide evidence of style based investing across value/growth, size, and, somewhat more weakly, cyclical/defensive dimensions. We find that investors organize their trades along the size and value/growth dimensions switching importantly between opposing ends of each spectrum. 


\section{Correlations of styles flow and return: Evidence across different horizons.}

While the results from the previous section are consistent with the sentiment story of Barberis and Shleifer (2003), there is nothing to rule out that the flows we observe are correlated with the release of fundamental information. Indeed, without having explored the interaction between return and flow, we cannot even rule out the view that the flows we observe are totally unrelated to returns, and therefore of little consequence for equilibrium.

Thus, we turn to the relationship between style flow and return. Following Froot and Ramadorai (2003), we divide the empirical possibilities into three hypotheses. First is that the institutional investor flows we observe are uninteresting in that they are not related to prices at any horizons or at any leads and lags. Fundamentals affect prices, but flows do not, so we call this the "fundamentals-only view." Second is that the flows represent investors reactions to some form of fundamental information, whose innovations permanently impact prices. Here flows appear to have permanent impacts on returns; this is called the "strong flow-centric view." And third is that these investor flows do impact prices, but in a transitory, rather than permanent, way.

This last hypothesis - which Froot and Ramadorai (2003) call the "weak flowcentric view" - is most consistent with sentiment-driven models of trading. Barberis and Shleifer (2003) in particular, make a number of specific predictions for the contemporaneous and non-contemporaneous correlations between flows and returns. Their model predicts positive contemporaneous correlations because style investors take liquidity from the market to satisfy their sentiment-driven demands. It predicts that sentiment-driven flows will chase previous returns, and that flows can predict positively short horizon returns. However, any such positive predictability does not survive to long horizons. Current prices are unaffected by sentiment-driven flows from the sufficiently distant past. Consequently, at long horizons, flows and returns become unrelated: permanent innovations to fundamentals are uncorrelated with sentiment driven flows, but account for virtually all return variation. For this to occur, non-contemporaneous correlations between flows and returns must be negative at longer horizons. In sum, the 
weak flow-centric view predicts increasingly positive covariation between returns and flows at short horizons, but as horizons grow longer, the positive covariation disappears.

In this subsection, we examine correlations between the flows and returns of the five style dimensions. By stacking the ten deciles of each dimension, we are able to use the panel to gain power for relatively longer horizons. We therefore measure contemporaneous correlations over horizons ranging from 1 to 1000 trading days (approximately 4 years). Broadly speaking, the strong flow-centric view suggests a positive return/flow correlation at short horizons that remains equally and perhaps more positive at long horizons. By contrast the weak flow-centric view predicts that the positive return/flow correlation at short horizons is mostly undone at longer horizons.

Figure 3 graphs the point estimates as well as the $90 \%$ confidence bounds for the size, value/growth, cyclical/defensive, sector, and country/region style classifications respectively. The 90\% confidence bounds are derived from Monte Carlo simulations assuming that returns and flows are i.i.d. processes with daily contemporaneous correlations set equal to the observed daily correlations in the data. Details of this methodology can be found in the Appendix.

The figure shows that the short horizons contemporaneous correlations are positive for all 5 style dimensions. In addition, all 5 show evidence of statistically positive non-contemporaneous correlations at frequencies from a week to a month. This is evident from the fact that the return/flow correlation rises above the $90 \%$ Monte Carlo upper bound. Such non-contemporaneous correlation must arise from some combination of positive trend-flowing (current style flows positively correlated with past style returns) and anticipation (current style flows positively correlated with future style returns).

The figures also suggest that the impact of some style flows is more permanent than others. Value/growth and sector flows show relatively strong evidence that the positive correlation observed at high frequencies remains in tact at lower frequencies. There is no evidence of negative non-contemporaneous correlations. However, size flows, and to a lesser extent regional flows, seem to show evidence of negative-noncontemporaneous correlations. For size and region, there is little evidence that the long horizon correlation between flow and return is positive. This may suggest that sentimentdriven demand is relatively more important in size and regional flow styles than in 
value/growth and sector flows. Value/growth and sector segment flows may contain more information about fundamentals than other style flows. The size and sector style results accord with intuition, which suggests that the former should be relatively more sentiment-driven, and less fundamentals driven, than the latter.

In the subsequent sections, we explore further the impact of fundamentals on the relationship between style flows and returns. Also, it will be instructive to determine if the positive linkage we observe is due to positive feedback trading or to anticipation by institutional investors or to both.

\section{Non-contemporaneous correlations: style flows and future stock returns}

In the previous section, we document a strong positive non-contemporaneous relationship between style flows and style returns. Do these positive noncontemporaneous correlations arise from trend-chasing (returns positive predicting flows) or anticipation (flows positively predicting returns)? Evidence for the former has been more abundant in the literature than evidence for the latter (see Froot, O'Connell, and Seasholes, 2001; and Froot and Ramadorai, 2003).

If sentiment-driven style flows are sufficiently large and persistent, they may both affect prices and expected returns. Short-term price momentum and long-term price reversals are consistent with the weak flow centric view, as style-driven investors slowly reallocate back and forth between competing style segments, depending on their relative returns. These effects are at the level of styles, not of individual stocks, and therefore should be present after conditioning on standard own-stock characteristics.

If our institutional investors behave like the style-driven investors in Barberis and Shleifer (2003), nearby own-segment returns and flows should positively forecast stock returns while distant own-segment returns and flows should negatively forecast stock returns, after appropriate controls.

In what follows, we approximate nearby own-segment returns and flows as those of the decile portfolio (within a given style) to which a stock is assigned. We do this for 
each statistically-valid style (i.e., size, value/growth, sector, and region ${ }^{5}$ ). To see this, consider a stock that is in the first size decile, the second value/growth decile, and the third sector. We measure own-segment flows and returns using the value-weighted returns and flows of each own-segment for each style separately. So for nearby ownsegments for this stock we would look to the returns and flows from the first size decile, the second value/growth decile, and the third sector. At short horizons, we expect ownsegment flows and returns to forecast returns positively under both the strong and weak flow-centric views. At longer horizons, however, we would expect this result to reverse under the weak flow-centric view only.

To approximate distant own segment returns, we form the intersection of all size, value/growth, and sector segments that are not own-segment. We call the resulting measures "conjugate" flows and returns, since they represent the total flows and returns of collected non-own-segments. To continue with the above stock example, we would compute the flows and returns on the combined portfolio consisting of all stocks that were not in the first size decile, and not in the second value/growth decile, and not in the third sector. This way we are assured to include in our conjugate segment measures only stocks that differ across all dimensions from the own-stock. At short horizons, we expect conjugate flows and returns to forecast returns negatively under both the strong and weak flow-centric views. At longer horizons, we would expect this result to reverse under the weak flow-centric view only, so that conjugate flows and returns predict individual stock returns positively.

The presence of these style-level anticipation effects can be most directly tested by estimating a cross-sectional regression on stock returns with past returns and flows of both stock and style. To this end, we estimate the following OLS firm fixed effects regression ${ }^{6}$ on firm weekly stock returns for the set of firms that are frequently traded in our sample (firms with trades for at least 150 days a year over the entire sample ${ }^{7}$ ). We estimate two versions of this equation, one with a more extensive lag structure:

\footnotetext{
${ }^{5}$ We drop from this analysis the cyclical/defensive style because of the weak results obtained for that style category in Sections II.A. and II.B.

${ }^{6}$ To check that the extreme data points are not driving our results, we also try estimating a FGLS panel regression. Inferences do not change with this alternative specification.

${ }^{7}$ Firms with at least 150 trading days per year in the State Street Bank sample are chosen to adequately measure the effects of flows. We also re-estimate the regressions on the subset of firms with at least 100
} 


$$
\begin{aligned}
r_{i, t}=a_{1}^{\text {stock }} r_{i, t-1}+d_{1}^{\text {stock }} & f_{i, t-1}+a_{1}^{m e} r_{i, t-1}^{m e}+d_{1}^{m e} f_{i, t-1}^{m e}+a_{1}^{b m} r_{i, t-1}^{b m}+d_{1}^{b m} f_{i, t-1}^{b m}+a_{1}^{\text {ind }} r_{i, t-1}^{\text {ind }}+d_{1}^{\text {ind }} f_{i, t-1}^{\text {ind }} \\
& +a_{1}^{\text {conj }} r_{i, t-1}^{c o n j}+d_{1}^{\text {conj }} f_{i, t-1}^{c o n j}+a_{1}^{\text {gconj }} r_{i, t-1}^{\text {gconj }}+d_{1}^{\text {gconj }} f_{i, t-1}^{\text {gconj }} \\
& +b_{\text {char }}^{b m} M E_{i, t-1}+b_{c h a r}^{b m} B M_{i, t-1}+b_{c h a r}^{\text {roe }} R O E_{i, t-1}+\varepsilon_{i, t}
\end{aligned}
$$

Model 1

$$
\begin{aligned}
& r_{i, t}=a_{1}^{\text {stock }} r_{i, t-1}+d_{1}^{\text {stock }} f_{i, t-1}+a_{1}^{m e} r_{i, t-1}^{m e}+d_{1}^{m e} f_{i, t-1}^{m e}+a_{1}^{b m} r_{i, t-1}^{b m}+d_{1}^{b m} f_{i, t-1}^{b m}+a_{1}^{\text {ind }} r_{i, t-1}^{\text {ind }}+d_{1}^{\text {ind }} f_{i, t-1}^{\text {ind }} \\
& +a_{2,4}^{\text {stock }} r_{i, t-2, t-4}+d_{2,4}^{\text {stock }} f_{i, t-2, t-4}+a_{2,4}^{m e} r_{i, t-2, t-4}^{m e}+d_{2,4}^{m e} f_{i, t-2, t-4}^{m e}+a_{2,4}^{b m} r_{i, t-2, t-4}^{b m}+d_{2,4}^{b m} f_{i, t-2, t-4}^{b m}+a_{2,4}^{\text {ind }} i_{i, t-2, t-4}^{\text {ind }}+d_{2,4}^{\text {ind }} f_{i, t-2, t-4}^{\text {ind }} \\
& +a_{5,12}^{\text {stock }} r_{i, t-5, t-12}+d_{5,12}^{\text {stock }} f_{i, t-5, t-12}+a_{5,12}^{m e} r_{i, t-5, t-12}^{m e}+d_{5,12}^{m e} f_{i, t-5, t-12}^{m e}+a_{5,12}^{b m} r_{i, t-5, t-12}^{b m}+d_{5,12}^{b m} f_{i, t-5, t-12}^{b m}+a_{5,12}^{\text {ind }} r_{i, t-5, t-12}^{\text {ind }}+d_{5,12}^{\text {ind }} f_{i, t-5, t-12}^{\text {ind }} \\
& +a_{1}^{\text {conj }} r_{i, t-1}^{c o n j}+d_{1}^{\text {conj }} f_{i, t-1}^{c o n j}+a_{1}^{\text {gconj }} r_{i, t-1}^{\text {gconj }}+d_{1}^{\text {gconj }} f_{i, t-1}^{\text {gconj }} \\
& +a_{2,4}^{c o n j} r_{i, t-2, t-4}^{c o n j}+d_{2,4}^{c o n j} f_{i, t-2, t-4}^{c o n j}+a_{2,4}^{\text {gconj }} r_{i, t-2, t-4}^{g c o n j}+d_{2,4}^{\text {gconj }} f_{i, t-2, t-4}^{\text {gconj }} \\
& +a_{5,12}^{c o n j} r_{i, t-5, t-12}^{c o n j}+d_{5,12}^{c o n j} f_{i, t-5, t-12}^{c o n j}+a_{5,12}^{\text {gconj }} r_{i, t-5, t-12}^{g c o n j}+d_{5,12}^{\text {gconj }} f_{i, t-5, t-12}^{\text {gconj }} \\
& +b_{c h a r}^{b m} M E_{i, t-1}+b_{c h a r}^{b m} B M_{i, t-1}+b_{c h a r}^{r o e} R O E_{i, t-1}+\varepsilon_{i, t}
\end{aligned}
$$

----- Model 2

where $r_{i, t}$ is the return to stock $i$ at week $t$ in excess of the market, $r_{i, t}^{m e}$ is the excess return to stock $i$ 's size segment, $r_{i, t}^{b m}$ is the excess return to stock $i$ 's value/growth segment, $r_{i, t}^{\text {ind }}$ is the excess return to stock $i$ 's sector segment, $r_{i, t}^{c o n j}$ is the excess return to stock $i$ 's domestic conjugate segment, and $r_{i, t}^{\text {gconj }}$ is the excess return to stock $i$ 's global conjugate segment. The flow variables are defined analogously. $M E, B M$, and $R O E$ are stock control variables for own-stock market equity, book-to-market, and return on equity, respectively. The time subscripts $t-2, t-4$ denotes that regressors are averaged across last 2 through 4 weeks (i.e., the remainder of the month following $t-1$ ), and time subscript $t-5, t-12$ denotes that regressors are averaged across last 5 through 12 weeks. Domestic conjugate segment attributes are taken over the set of firms not in the size, value/growth, and sector segments that the firm belongs to. Global conjugate segment attributes are taken over all the non-US countries/regions.

The coefficient estimates from the regressions are displayed in Table IV with $t$ statistics from standard errors corrected for cross-sectional heteroskedasticity (Beck and

trading days a year, and the subset of firms with at least 200 trading days a year. The results in both cases are qualitatively very similar to the baseline case. In response to survivorship concerns, we also redo the analysis on firms with at least 150 trading days in any year. The results are robust to this adjustment. 
Katz, 1995). They are broadly consistent with the flow-centric views of style investing. For Model 1, which only includes regressors lagged one week, own segment returns and flows positively forecast weekly stock returns. The coefficients show, for example, that a one standard deviation increase in value/growth previous-week return increases currentweek expected stock returns by 3.95 basis points. Likewise, a one standard deviation increase in value/growth flow last week increases expected stock returns this week by 15.4 basis points. Similar results obtain for the size returns and flows, and the sector segment returns and flows. Further the coefficient estimates for the conjugate variables contrast with the coefficient estimates for the own segment variables. Conjugate returns and flows, as well as global conjugate returns and flows negatively forecast stock returns. A one standard deviation increase in conjugate returns one week ago is associated with a 2.85 basis point drop in expected stock returns this week. One possible interpretation is that investors flock to the conjugate segments when conjugate segments post higher returns than own segments, thereby driving down the price of the stock.

Model 2 features regressors with three different horizons: Regressors lagged 1 week, lagged $2-4$ weeks, and lagged $5-12$ weeks. This way the model captures variation over the last week, the last month (excluding the last week), and the last quarter (excluding the last month). We restrict the coefficients on the aggregated lags to be equal, to keep the number of variables down and their interpretability high. The results from the longer lags of the independent variables broadly suggest that the positive effects of own style variables and the negative effects of conjugate style variables are transient. Longer lags of own segment returns and flows often negatively forecast stock returns. For instance, a one standard deviation increase in average sector segment returns 5-12 weeks ago is associated with a 6.95 basis point drop in expected stock returns this week. Similarly, a one standard deviation increase in average sector segment flows 5-12 weeks ago is associated with a 1.25 basis point fall in expected stock returns. The negative effects are less dramatic for size and value/growth segments but a clear pattern emerges. Either we see a fall in the strength of the coefficients as we increase the lag or we find that beyond the first week lag, some of the coefficient estimates are negative. The presence of reversals at the monthly or quarterly horizon is also evident with conjugate and global conjugate segment returns and flows. 
Note that the regression controls for the own stock returns and flows, and thus the style effects we witness in Table $\mathrm{V}$ are over and above that generated by stock attributes. Since we also control for the stock's book-to-market equity and market equity (Fama and French, 1992). The results displayed in Table V suggest that the style effects persist after controlling for these possible sources of fundamental risk. In addition, both models include controls for ROE since according to Haugen and Baker (1996), controlling for other firm characteristics, firms with higher profitability exhibit higher returns. We follow Haugen and Baker (1996) and use Generally Accepted Accounting Principles (GAAP) ROE instead of clean surplus ROE.

We note also that the positive coefficient estimates on the past week's own segment flows suggest that institutional investors positively anticipate returns - positive segment flows precede positive segment returns. Hence some of the positive noncontemporaneous correlations between segment returns and flows in the last section are due to anticipation effects. To check the presence of positive feedback trading, we also regress stock flow on the same list of regressors in Model 2. We find that institutional investors do indeed positively chase returns at the style level, at least for the size and value / growth classifications. So both positive feedback trading and anticipation must be responsible for the positive non-contemporaneous correlations between segment flow and returns.

Overall, the results from this simple regression exercise suggests that the style effects (short term style driven momentum, and to a lesser extent, longer term style driven reversals) are consistent with sentiment based stories like Barberis and Shleifer (2003). This is particular true when we consider the conjugate style results. The negative coefficients on conjugates suggest that this is not a fundamentals story. It is hard to say why it should be that when the fundamentals improve for one extreme (e.g., extreme value), that they should get worse for the other extreme (e.g., extreme growth). The sentiment based story explains this nicely. When extreme growth performs better than extreme value, positive feedback style switchers pull money away from the extreme value and plough those funds into extreme growth.

It is important to square the panel regression results from this section with the style return and flow correlation results from the previous section. There we found that 
the correlation between style return and flow increases as we approach the quarterly horizon. Yet, in the simple panel regressions, we find that style level momentum starts to give way to style level reversals as we approach the quarterly horizon. One reason for this apparent dissonance is that we control for stock fundamentals in the panel regression. That is we attempt to strip away from style flows that which affects the permanent component of stock returns. Style flows have a more durable impact on style returns in the correlation analysis precisely because they may contain some information about stock fundamentals. We empirically check this by estimated regressions on stock returns with just the style flow lags for size, value/growth, and sectors, one style at a time. We find that the evidence for style level reversals is always less than that from the multivariate regression (Model 2). One other reason for the apparent dissonance is that the correlation contains information, not just on how lags of style flow affects style returns, but also information on the contemporaneous relationship between style flow and return as well as the impact of lags of style returns on style flows. That is,

$$
\operatorname{Corr}\left(r_{t}+r_{t+1}, f_{t}+f_{t+1}\right)=\frac{\operatorname{Cov}\left(r_{t}, f_{t}\right)+\operatorname{Cov}\left(r_{t+1}, f_{t+1}\right)+\operatorname{Cov}\left(r_{t}, f_{t+1}\right)+\operatorname{Cov}\left(r_{t+1}, f_{t}\right)}{\operatorname{Var}\left(r_{t}+r_{t+1}\right) * \operatorname{Var}\left(f_{t}+f_{t+1}\right)}
$$

Even if the term $\operatorname{Cov}\left(r_{t+1}, f_{t}\right)$ is negative, the presence of positive feedback trading and price impact may result in a positive correlation between style flow and style return.

The results thus far have focused on the short-term dynamics between stock returns and style returns/flows. We find some evidence of style driven reversals at quarterly horizons. To further a style-based sentiment story, it may be useful to investigate the presence of style reversals at longer horizons. However, the nature of our dataset (high frequency with a short time series) prevents us from fully doing so. Nonetheless, in results not reported, we experiment with adding up to two years of annual lags of style variables in our simple panel regressions. We find strong evidence of stylelevel reversals with style returns at the one and two year horizons, but mixed evidence for style-level reversals with style flows. This is broadly consistent with Teo and Woo (2003) who also find stronger evidence for reversals with style returns. One interpretation is that style flows contain more information about stock fundamentals (unrelated to stock characteristics and past stock returns/flows) than style returns. Another interpretation is 
that style level reversals do not fully occur until after two years. We shall revisit this issue in the next section.

\section{E. Style-Based Flow/Return Dynamics}

Not withstanding the conjugate results of the last section, one critique of the simple regression approach is that it does not fully account for the possibility that style flows and returns may also affect the permanent component of returns that is not spanned by stock characteristics and past stock returns/flows. To thoroughly distinguish from any fundamentals based story, it will be important to isolate the effects of styles on the temporary component of stock returns. It is to this that we now turn.

\section{E.1. The VAR}

To further investigate the interaction between style returns, style flows, and stock fundamentals, we apply Campbell's (1991) return decomposition to break stock returns into a permanent cash flow component and a temporary expected return component.

$$
r_{t}-E_{t-1} r_{t}=\left(E_{t}-E_{t-1}\right) \sum_{j=0}^{\infty} \rho^{j} e_{t+j}-\left(E_{t}-E_{t-1}\right) \sum_{j=0}^{\infty} \rho^{j} r_{t+j}+\kappa_{t}
$$

where $\rho$ is the weekly discount rate which we set to $0.998, e_{t}$ is the clean surplus accounting return on equity in period $t, r_{t}$ is the return of the stock in period $t$, and $\kappa_{t}$ is the approximation error in period $t$. The term $\left(E_{t}-E_{t-1}\right) \sum_{j=0}^{\infty} \rho^{j} e_{t+j}$ is the permanent cash flow news component of returns, while the term $\left(E_{t}-E_{t-1}\right) \sum_{j=0}^{\infty} \rho^{j} r_{t+j}$ is the temporary expected return news component of returns.

This decomposition proves useful in many situations. Campbell and Shiller (1988) and Campbell (1991) use this decomposition on aggregate equity returns to show 
that expected return news dominates cash flow news in the post-war period. In contrast, Vuolteenaho (2002) finds using this decomposition that cash flow news dominate expected return news for individual stocks. Cohen, Gompers, and Vuolteenaho (2003) reach similar conclusions. They also document that institutional investors underreact to cash flow news and do not follow naive positive feedback strategies. Institutional investors buy when there is good cash flow news but sell when stock returns rises in the absence of good cash flow news. Froot and Ramadorai (2003) derive a similar decomposition for currency returns, although their exchange rate derivation does not require any approximation, i.e., $\rho=1$ and $\kappa=0$. Froot and Ramadorai (2003) use the decomposition to show that institutional investor flows are positively correlated with the temporary component but not with the permanent component of currency returns.

Our primary aim is to investigate the effects of style returns and flows on stock returns controlling for permanent cash flow shocks. The expected return regressions using style flow from the previous section control for stock characteristics like book-tomarket and market equity. However, if we wish to distinguish between the strong and weak flow-centric views, such simple controls are not enough. It is more appropriate to use the decomposition above. The weak flow-centric view suggests that style flows should be related to the temporary component of returns, while the strong flow-centric view suggests that the style flows are related only to the permanent component of value. As a result, we use a VAR to affect the above decomposition into permanent and transitory return components.

The state variables in our VAR are own-stock return and flow, size segment return and flow, value/growth segment return and flow, sector segment return and flow, US conjugate return and flow, and global conjugate return and flow. In addition, we include in the VAR standard stock characteristics of log stock book-to-market equity, log stock market equity, and log GAAP ROE. We include these characteristics in response to the documented explanatory power of these variables on stock returns. ${ }^{8}$

\footnotetext{
${ }^{8}$ Fama and French (1992) find that high book-to-market stocks tend to reward investors with higher returns. Banz (1981) document the existence of the size effect. Haugen and Baker (1996) show that firms with higher profitability ten to have higher average returns after controlling for other firm attributes. We follow Haugen and Baker (1996) and use Generally Accepted Accounting Principles (GAAP) ROE instead of clean surplus ROE.
} 
Because the number of unrestricted VAR coefficients increases with the square of the number of variables included in the VAR, we estimate a constrained system using the lag structure of Model 1. The constraint is simple: all stock flow, stock return, and stock characteristic coefficients are set to zero for the style attribute equations. Thus, we are implicitly making the assumption that each stock has only a negligible effect on its segment return or flow.

The VAR system can be conveniently summarized by the following equation:

$$
z_{i, t}=\Gamma z_{i, t-1}+u_{i, t}
$$

where $z_{i, t}$ is a vector of firm-specific state variables describing the firm at time $t$, and $u_{i, t}$ is an error term which is independent of information available at time $t-1$ and which has covariance matrix of $E\left[u_{t} u_{t}^{\prime}\right]=\Sigma$. If we let the first variable in the vector be own-firm excess return, and define $e 1^{\prime}=\left[\begin{array}{llll}1 & 0 & \ldots & 0\end{array}\right]$ and $\lambda^{\prime}=e 1^{\prime} \rho \Gamma(I-\rho \Gamma)^{-1}$, then as shown by Campbell (1991), the temporary expected return component can be written as $\lambda^{\prime} u_{i, t}$ and the permanent cash flow component can be written as $\left(e 1^{\prime}+\lambda^{\prime}\right) u_{i, t}$.

The VAR impulse response allows us to identify how shocks affect expected innovations. Specifically, the innovation in cumulative expected future changes $k \geq 1$ periods forward is given by $\Phi(k) u_{t}$, where

$$
\Phi(k) u_{t}=\left(\Gamma-\Gamma^{k+1}\right)(I-\Gamma)^{-1} u_{t} .
$$

We pick out cumulated expected changes in any VAR variable by pre-multiplying by the appropriate selection vector. For example, the innovation in the cumulated expectations of the first variable, stock returns, is given by $e 1^{\prime} \Phi(k) u_{t}$. Analogously, the innovation in cumulated expectations of the second variable, own-stock flows, is given by $e 2^{\prime} \Phi(k) u_{t}$ where $e 2^{\prime}=\left[\begin{array}{llll}1 & 0 & \ldots & 0\end{array}\right]$. The total impulse response from a shock to stock returns is the sum of the innovation in cumulative expected future return changes, $e 1^{\prime} \Phi(k) u_{t}$, plus the shock itself, $e 1^{\prime} u_{t}$, or 


$$
e 1^{\prime} \Psi(k) u_{t}=e 1^{\prime}(\Phi(k)+I) u_{t}
$$

where $\Psi(k)=(\Phi(k)+I)$.

\section{E.2. Results}

Our baseline results are displayed in Figures $4 \mathrm{a}$ and $4 \mathrm{~b}$, where we depict the expected response of stock returns to shocks in the style variables. The impulse response functions together with their associated standard errors are broadly consistent with the regression results of the previous section. Own size, value/growth, and sector segment returns and flows positively impact the stock returns, while conjugate and global conjugate segment returns and flows negatively impact stock returns. Moreover the short term impact on stock returns is statistically significant for all shocks except for the shock to sector returns which generates an insignificantly positive impact on stock returns. This mirrors the sector return coefficient estimate from Model 1 in Table V.

The transient effect of style is evident in some cases. The three basis points impact of a one standard deviation value/growth segment return shock on stock returns diminishes and becomes insignificant beyond the first week. Likewise the negative shocks generated by conjugate return and global conjugate return shocks become attenuated after the first week. However, in almost every case, the shocks to style variables appear to create permanent changes in stock return. For instance, a one standard deviation size segment return shock leaves a permanent six basis point increase in expected stock return in its wake. Similarly, a one standard deviation size segment flow shock generates a permanent five basis point increase in expected stock return. This suggests that the style variables may embody fundamental information about a stock and is supportive of the strong flow-centric view.

Fortunately, we can also use this approach to test for the presence of the weak flow-centric view. We can examine the impact of our style variables on temporary component of stock returns in isolation. To this end, we plot the typical impulse responses of stock returns to shocks in the style variables when there is no change in cash 
flow news - i.e., when the unexpected return shock is entirely temporary in that it is offset by a corresponding change in forecasted future return. We induce this shock by setting the appropriate element of the VAR error vector to a one standard deviation value, with other elements set to their conditional expectations (i.e., conditional on the style variable element being at its one standard deviation value and cash flow news being equal to zero). This ensures that we are measuring the effects of style on only the temporary component of stock returns.

The results displayed in Figures 5a and 5b are broadly consistent with the results from the "naïve" approach in the previous subsection. A positive shock to own size, value/growth, and sector segment returns and flows but with no corresponding change in cash flow news, induces a positive shock to stock returns. Furthermore, the impact of style return and flow shocks on stock returns is somewhat persistent in that stock returns typically continue to rise beyond the first week. This is certainly consistent with the weak flow-centric view. From Figure 6a, we see that the effect of an own-segment return/flow shock begins to dissipate only after about 10 days, although full elimination requires 300-400 weeks. The positive impacts of own-segment return shocks on stock returns generally dissipate more slowly than the impacts of own-segment flow shocks.

The conjugate segment return and flow results also agree with those using the naïve approach. Following a positive shock to either conjugate return or flow, stock returns decrease, even when setting cash flow shocks to zero. For example, a one standard deviation shock to conjugate segment return with no change in cash flow news is associated with a 10 basis point drop in expected stock return. This decline requires about 500 weeks to dissipate. The impact of a shock to global conjugate returns does not follow the sign of the naïve approach. Otherwise there is strong agreement between the two approaches.

In summary, the VAR based on the return decomposition gives essentially the same results as the naïve approach of the previous subsection. In both cases, ownsegment style returns have a positive effect on stock returns. Also conjugate style returns have a negative impact on stock returns. The negative impact of global conjugate return and flow on stock returns, documented in the previous section, is not robust to controlling for permanent shocks to stock price. 


\section{Conclusions}

This paper provides evidence that institutional investors organize and trade stocks in styles such value/growth, small/large, cyclical/defensive, sector/industries, and countries/regions. The paper uses high quality, high frequency daily trade flow data from State Street Corporation, covering all the trades of a very large and global group of institutional investors. We find strong evidence that investors reallocate intensively across size, value/growth, and sectors, but not across what we call cyclical vs. defensive, which sorts stocks on the basis of their past correlation with GNP growth up to one year ahead. All of these style classifications appear to be gaining in importance relative to international reallocation.

We also find a positive linkage between style returns and institutional style flows at the daily level, and this linkage grows stronger as the horizon is increased to several months. This positive relationship is predominantly, but not solely, due to positive feedback trading at the style level. We find that institutional style flows anticipate style returns as well. In fact, at weekly frequencies, own-segment style flows and returns positively forecast stock returns, while distant-segment flows and returns negatively forecast stock returns. These effects are reversed at the quarterly horizons and are robust to controls for stock flows and returns as well as stock characteristics.

These results are consistent with the weak flow-centric view, which suggests that flows, at least in part, are related to temporary components of prices. This view is supportive of several behavioral models, particularly that of Barberis and Shleifer (2003), who posit that trend chasing investors switch toward better-performing styles, and their interaction with rational investors produces short run momentum and longer run reversion.

Promising avenues for further research include investigating the emergence and evolution of styles, the relationship between individual fund characteristics and their style-related trades, and the trade-by-trade style-switching activities of institutional traders. 


\section{References}

Asness, Clifford S., John M. Liew, and Ross L. Stevens, 1997, Parallels between the cross-sectional predictability of stock returns and country returns, Journal of Portfolio Management 23, 79-87.

Banz, Rolf W., 1981, The relationship between return and market value of common stocks, Journal of Financial Economics 9, 3-18.

Barberis, Nicholas, and Andrei Shleifer, 2003, Style investing, Journal of Financial Economics 68, 161-199.

Barberis, Nicholas, Andrei Shleifer, and Jeffrey Wurgler, 2003, Comovement, Forthcoming in Journal of Financial Economics.

Beck, Nathaniel, and Jonathan N. Katz, 1995, What to do (and not to do) with timeseries-cross-section data in comparative politics. American Political Science Review, 89, 634-647.

Brennan, Michael J., and H. Henry Cao, 1997, International portfolio investment flows, Journal of Finance 52, 1851-1880.

Campbell, John Y., 1991, A variance decomposition for stock returns, Economic Journal $101,157-179$.

Campbell, John Y., and Richard H. Clarida, 1987, The dollar and real interest rates, Carnegie-Rochester Conference Series on Public Policy 27, 103-139.

Campbell, John Y., and Robert J. Shiller, 1988, The dividend-price ratio and expectations of future dividends and discount factors, Review of Financial Studies 1, 195-227.

Carhart, Mark, 1997, On persistence in mutual fund performance, Journal of Finance 52, $57-82$

Cavaglia, Stefano, Chris Brightman, and Michael Aked, 2000, The increasing importance of industry factors, Financial Analysts Journal Sep/Oct 2000, 56, 41-54.

Chen, Hsiu-lang, and Werner De Bondt, 2003, Style momentum within the S\&P 500 index, Forthcoming in Journal of Empirical Finance.

Cohen, Randy, Paul Gompers, and Tuomo Vuolteenaho, 2003, Who undereacts to cashflow news? Evidence from trading between individuals and institutions, Forthcoming in Journal of Financial Economics. 
Daniel, Kent, Mark Grinblatt, Sheridan Titman, and Russ Wermers, 1997, Measuring mutual fund performance with characteristic-based benchmarks, Journal of Finance 52, 1035-1058.

Fama, Eugene, and Kenneth French, 1992, The cross-section of expected stock returns, Journal of Finance 47, 427-465.

Fama, Eugene, and Kenneth French, 1993, Common risk factors in the returns on stocks and bonds, Journal of Financial Economics 33, 3-56.

Fama, Eugene, and Kenneth French, 1997, Industry costs of equity, Journal of Financial Economics 43, 153-193.

Froot, Kenneth, and Emily Dabora, 1999, How are stock prices affected by the location of trade? Journal of Financial Economics 53, 189-216.

Froot, Kenneth, Paul G. J. O'Connell, and Mark Seasholes, 2001, The portfolio flows of international investors, Journal of Financial Economics 59, 151-193.

Froot, Kenneth, and Tarun Ramadorai, 2003, Currency returns, intrinsic value, and institutional investor flows, Unpublished working paper. Harvard Business School.

Gompers, Paul, and Andrew Metrick, 2001, Institutional investors and equity prices, Quarterly Journal of Economics 116, 229-260.

Grinblatt, Mark, and Matti Keloharju, 2000, The investment behavior and performance of various investor-types: A study of Finland's unique data set, Journal of Financial Economics 55, 43-67.

Grinblatt, Mark, Sheridan Titman, Russ Wermers, 1995, Momentum investment strategies, portfolio performance, and herding: A study of mutual fund behavior, American Economic Review 85, 1088-1105.

Haugen, Robert A., and Nardin L. Baker, 1996, Commonality in the determinants of expected stock returns, Journal of Financial Economics 41, 401-439.

Hardouvelis, Gikas, Raphael La Porta, and Tierry Wizman, 1994, What moves the discount on country equity funds?, in Jeff Frankel, ed: The Internationalization of Equity Markets (University of Chicago Press, Chicago, Ill).

Kumar, Alok, 2002, Style switching and stock returns, Unpublished working paper. Cornell University. 
Lewellen, Jonathan, 2002, Momentum and autocorrelation in stock returns, The Review of Financial Studies 15, 533-564.

Moskowitz, Tobias, and Mark Grinblatt, 1999, Do industries explain momentum? Journal of Finance 54, 1249-1290.

Nofsinger, John R., and Richard W. Sias, 1999, Herding and feedback trading by institutional and individual investors, Journal of Finance 54, 2263-2295.

Teo, Melvyn, and Sung-Jun Woo, 2003, Style effects in the cross-section of stock returns, Forthcoming in Journal of Financial Economics.

Vuolteenaho, Tuomo, 2002, What drives firm-level stock returns? Journal of Finance 57, 233-264. 


\section{Appendix}

The methodology outlined below is analogous to that in Froot and Ramadorai (2003). Standard errors for correlation estimates are constructed using the Monte Carlo method. These correlation estimates are computed between flows and returns for the panel of $N$ segments and $\mathrm{T}$ days, $\rho(K)=\operatorname{cor}\left(r_{j, t}(K), F_{j, t}(K)\right), \quad$ where $j=1, \ldots, N$ and $t=1, \ldots, T$ at different return horizons $K$. Here, if $T$ is the number of days in the entire sample, and $N$ the number of segments in the panel, we compute correlations for all horizons $K$ between 1 and $T$. This means that for given $K$, the correlation is estimated using $(N T / K)$ observations, where each observation is the sum of $K$ time series elements in each segment. When $K=T$, the panel correlation is an $N \times 1$ cross-section, with each observation of flows representing the total net inflow over the entire sample period for a segment and each observation of returns representing the total excess segment return over the same period for the corresponding segment. When $K=1$, $\rho(K)=\rho(1)=\operatorname{cor}\left(r_{j, t}, F_{j, t}\right)$, the daily panel correlation, computed using NT observations for each of flows and returns.

To compute standard errors using the Monte Carlo method, we assume flows and returns are multivariate normal, with moments derived from our daily panel of flows and returns. Define $\mu_{f}=\frac{1}{N T} \sum_{j=1}^{N} \sum_{t=1}^{T} f_{j, t}, \mu_{r}=\frac{1}{N T} \sum_{j=1}^{N} \sum_{t=1}^{T} r_{j, t}$, and $\sigma_{f}^{2}, \sigma_{r}^{2}, \sigma_{f r}$, respectively, as the variance of daily flows computed across the panel, the variance of returns computed similarly; and the covariance between the daily panels of flows and returns. We draw $\omega_{f}$ and $\omega_{r}$ as simulated flows and returns, each a vector NTx 1 , from the multivariate normal distribution:

$$
\left(\begin{array}{c}
\omega_{f} \\
\omega_{r}
\end{array}\right) \sim N\left(\left(\begin{array}{l}
\mu_{f} \\
\mu_{r}
\end{array}\right),\left(\begin{array}{ll}
\sigma_{f}^{2} & \sigma_{f r} \\
\sigma_{f r} & \sigma_{r}^{2}
\end{array}\right)\right)
$$

Using these draws, we follow essentially the same procedure as above, treating the draws as our flow and return variables, and computing correlations at different return horizons $K$. We draw 10,000 such samples from the distribution and generate panel 
correlations for each return horizon using these draws. The results are then sorted to generate point-wise confidence intervals for our sample estimates at each return horizon. 

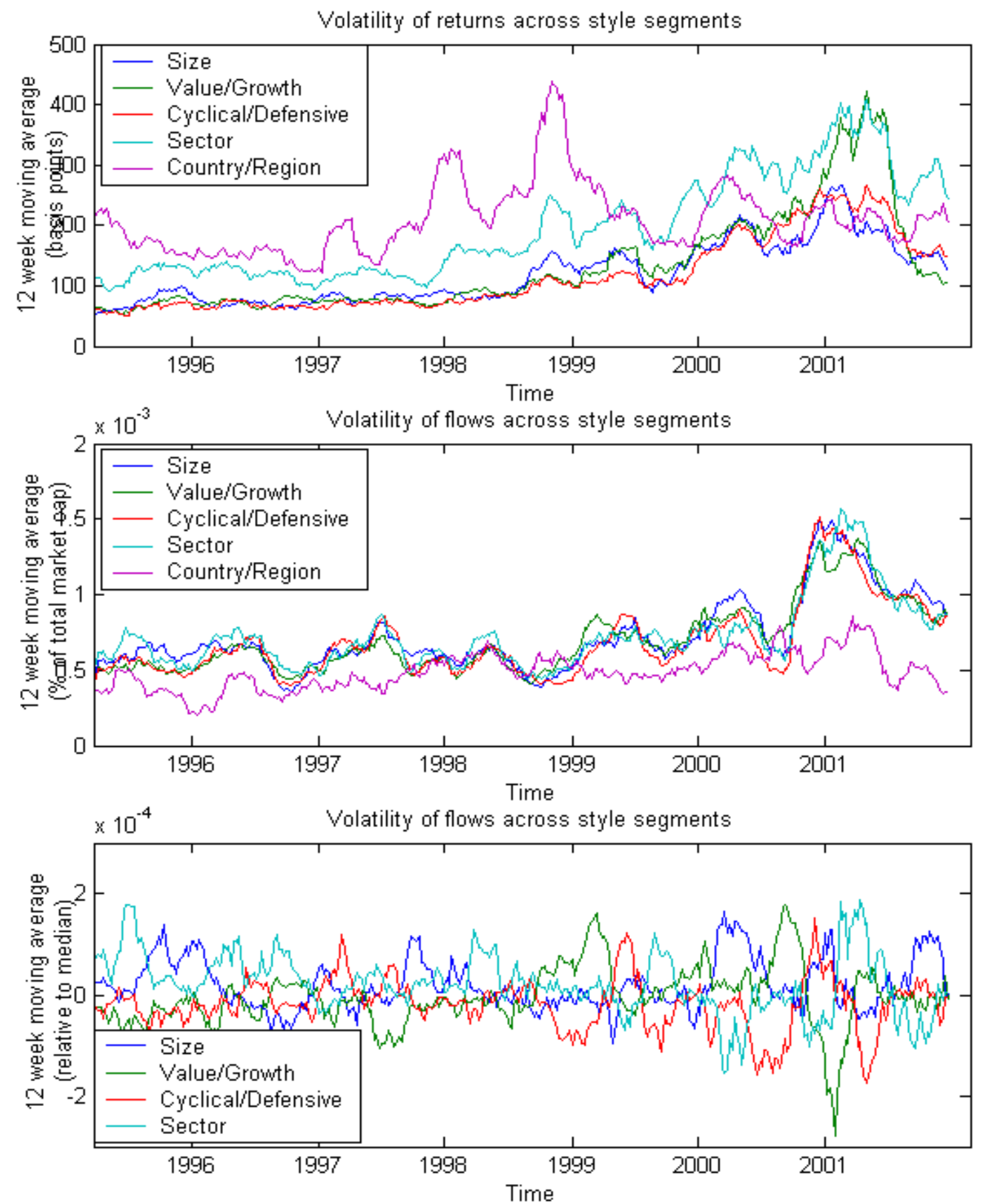

Figure 1: Volatility of returns and flows across style segments. The sample period is from January 1995 to December 2001. The top sub-figure plots the cross-sectional standard deviation in returns across each investment category. The middle and bottom sub-figures plot the volatility of flows or the re-allocation intensity for each investment category. Re-allocation intensity is a measure of institutional investor re-allocation across segments in a category. It is the cross-sectional standard deviation of demeaned excess flow over and above expected flow based on segment market cap (see Equation 1 in the text). Reallocation intensity is scaled by market cap to parse out the effect of increasing market cap on flows. 
Flow into extreme small and large size segments

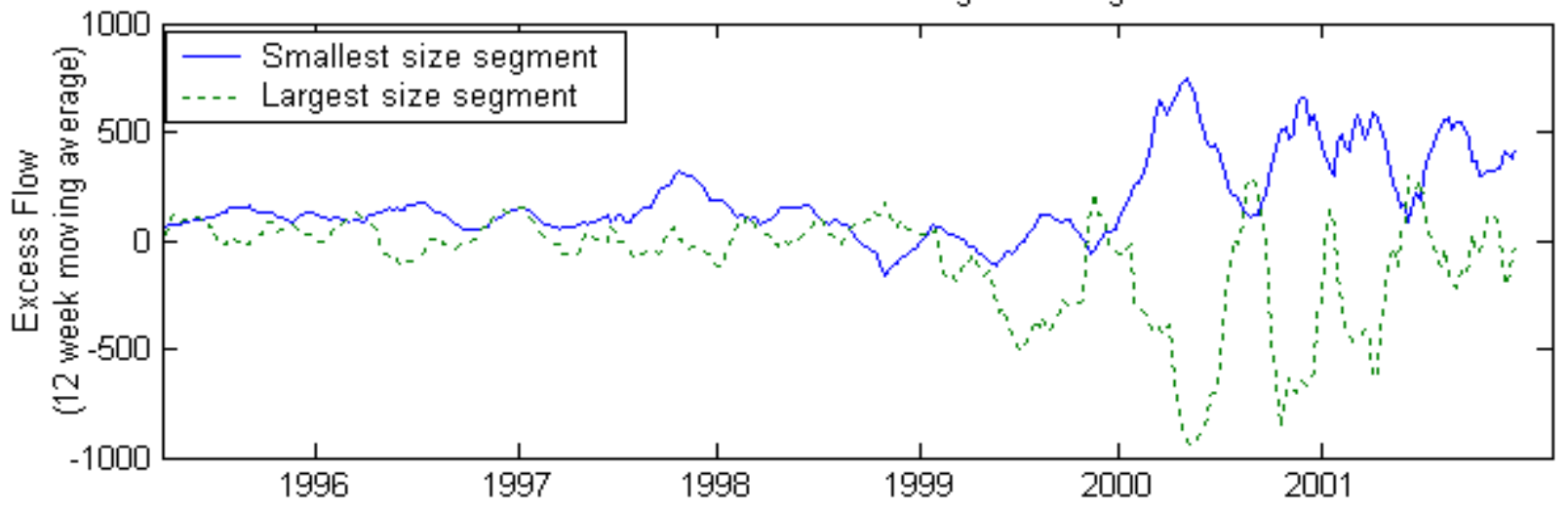

Flow into extreme value and growth segments

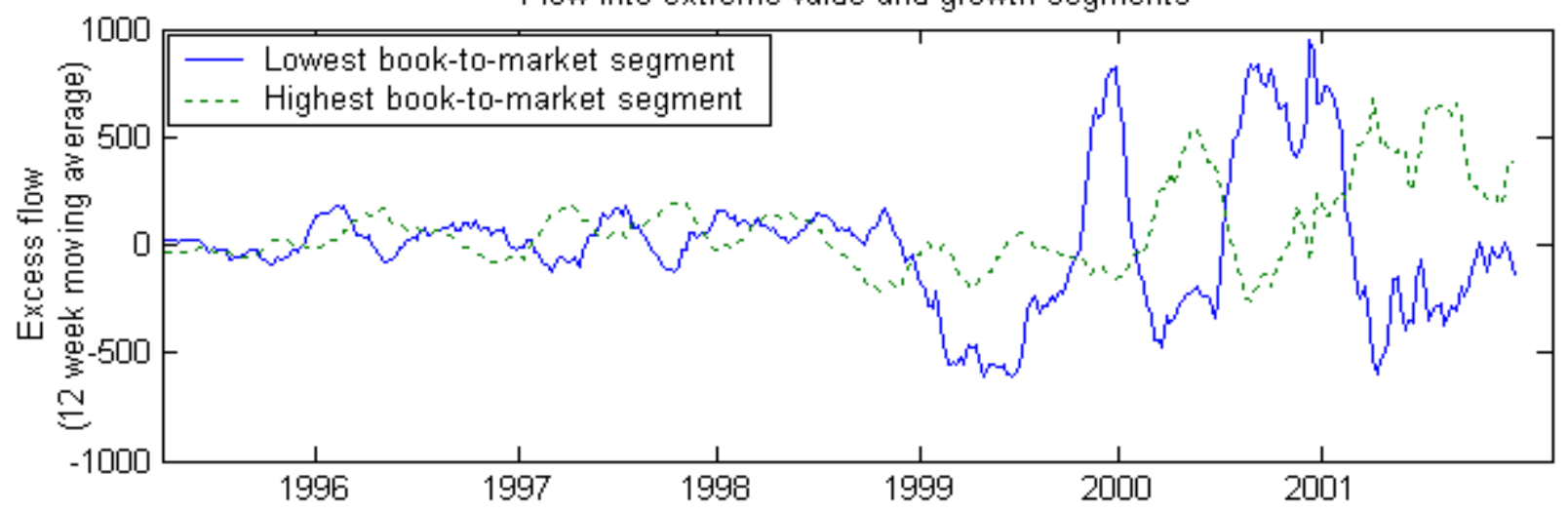

Flow into extreme cyclical and defensive segments

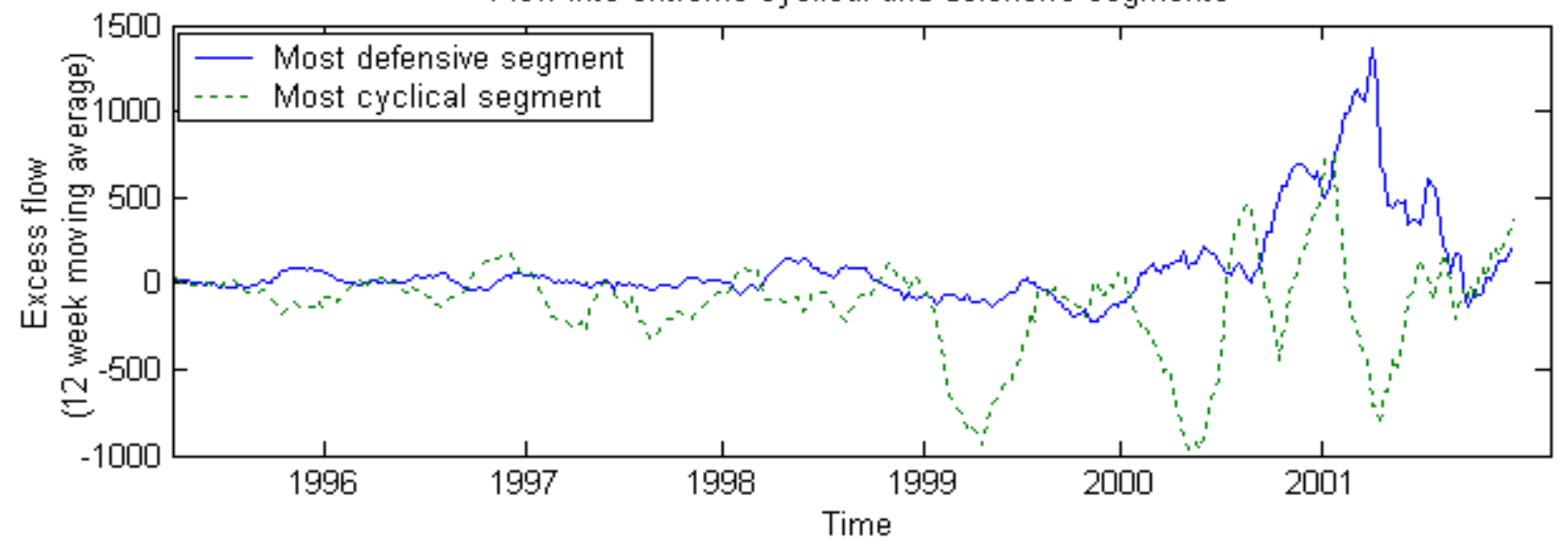

Figure 2: Institutional investor flow into extreme size, value/growth, and cyclical/defensive segments. The sample period is January 1995 to December 2001. The top sub-figure plots the excess flows into firms in the smallest and largest market equity deciles. The middle sub-figure plots the excess flows into firms in the lowest and highest book-to-market equity deciles. The bottom subfigure plots the excess flows into firms in the most defensive and most cyclical equity deciles. Excess flow is flow in excess of expected flow based on the market cap of the segment relative to the total market cap at each time period. 12 week (1 quarter) moving averages of the excess flows are presented. 

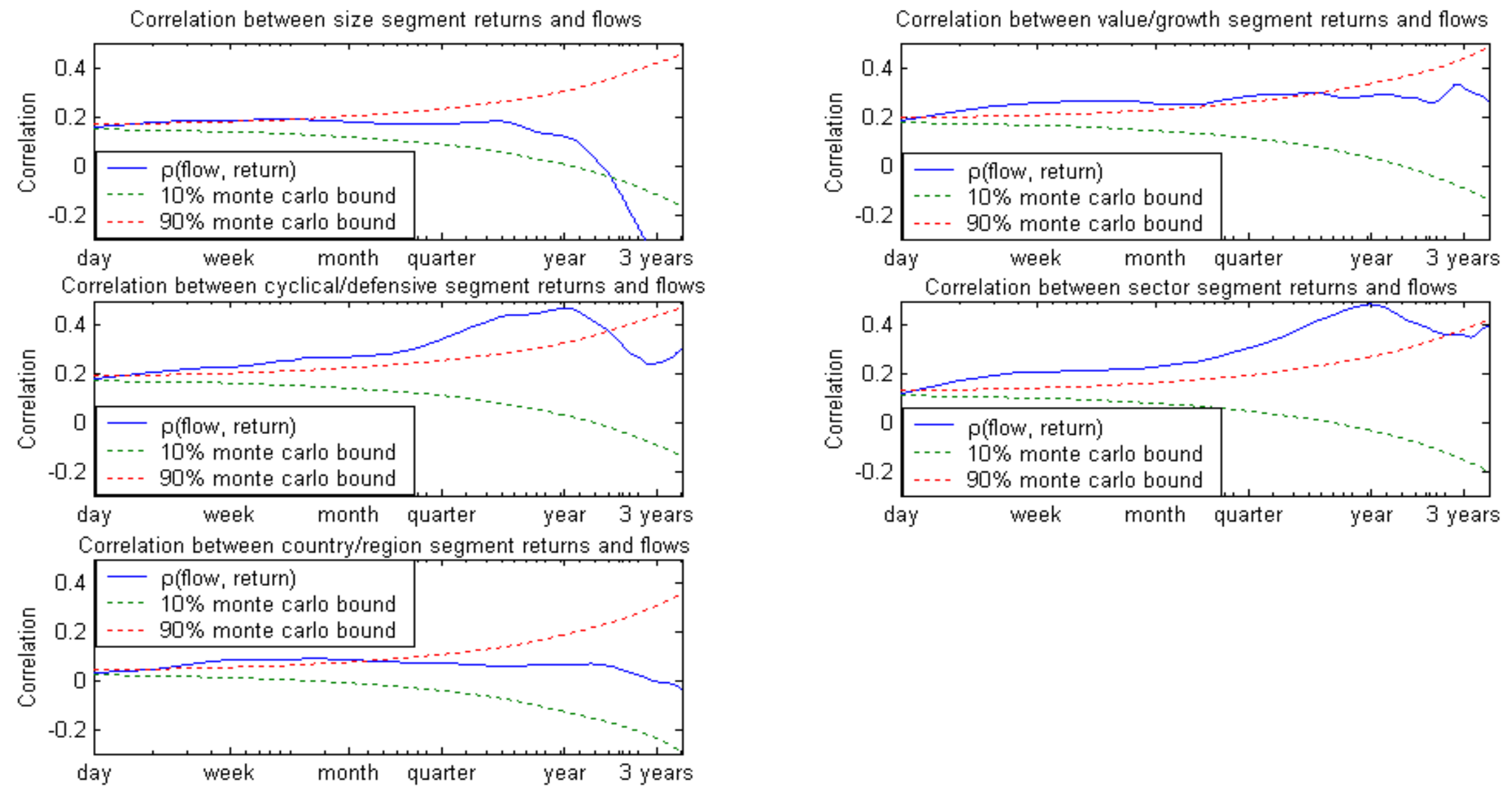

Figure 3: Contemporaneous correlation between returns and flows over various horizons for size, value/growth, cyclical/defensive, sector, and country/region segments. The sample period is from January 3rd 1995 to December 31st 2001. Return is excess return over the value-weighted US market portfolio. Flow is net inflow normalized by market equity. For each style, to calculate the sample correlation between flow and return, adjacent observations in each decile are summed up to the appropriate horizon in a non-overlapping fashion. Then the ten flow and ten return series are stacked and the correlation between the stacked flow and stacked return series is calculated. The procedure for calculating the Monte Carlo bounds is in the Appendix 

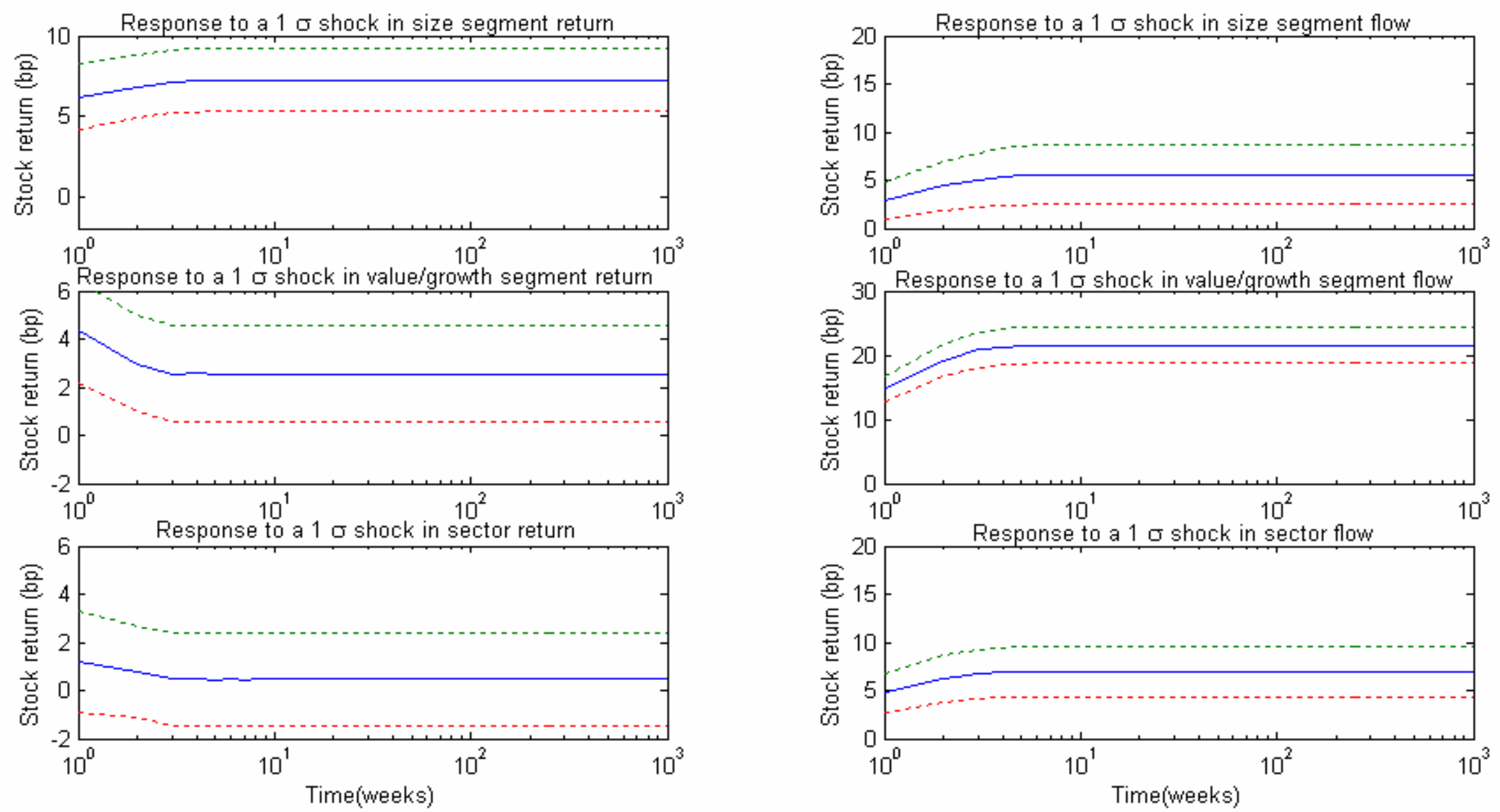

Figure 4a: Response of stock return to a one standard deviation shocks to own style variables. The sample period is from January 1995 to December 2001. The impulse responses are generated from a VAR estimated with the following state variables: Stock return, stock flow, stock ME, stock BM, stock ROE, size segment return, size segment flow, value/growth segment return, value/growth segment flow, sector return, sector flow, conjugate return, conjugate flow, global conjugate return, global conjugate flow. Dashed lines denote $+/-2$ standard error monte carlo bounds. 

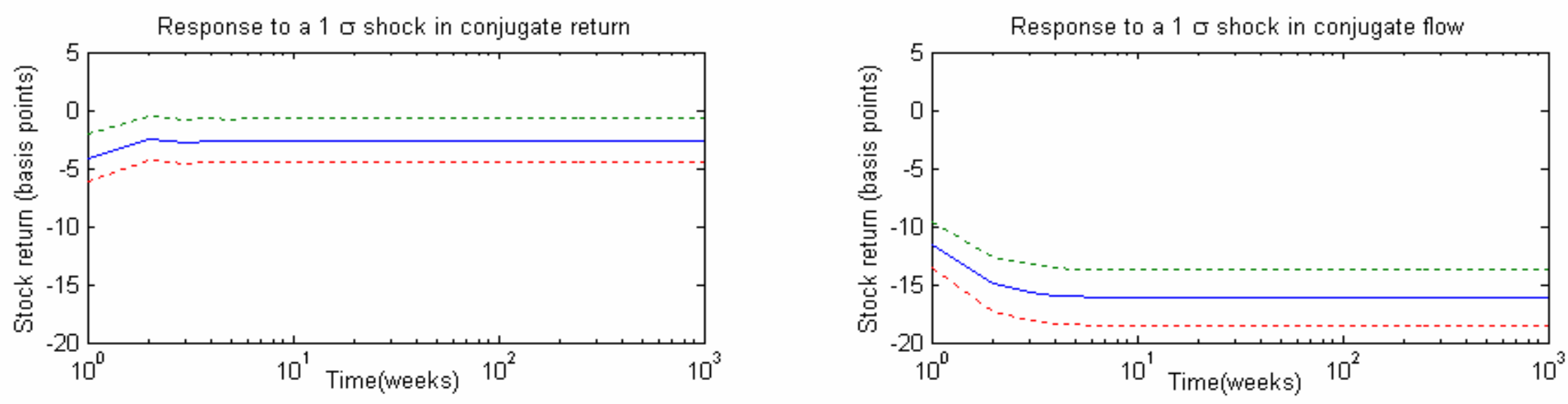

Response to a 1 a shock in Global conjugate return
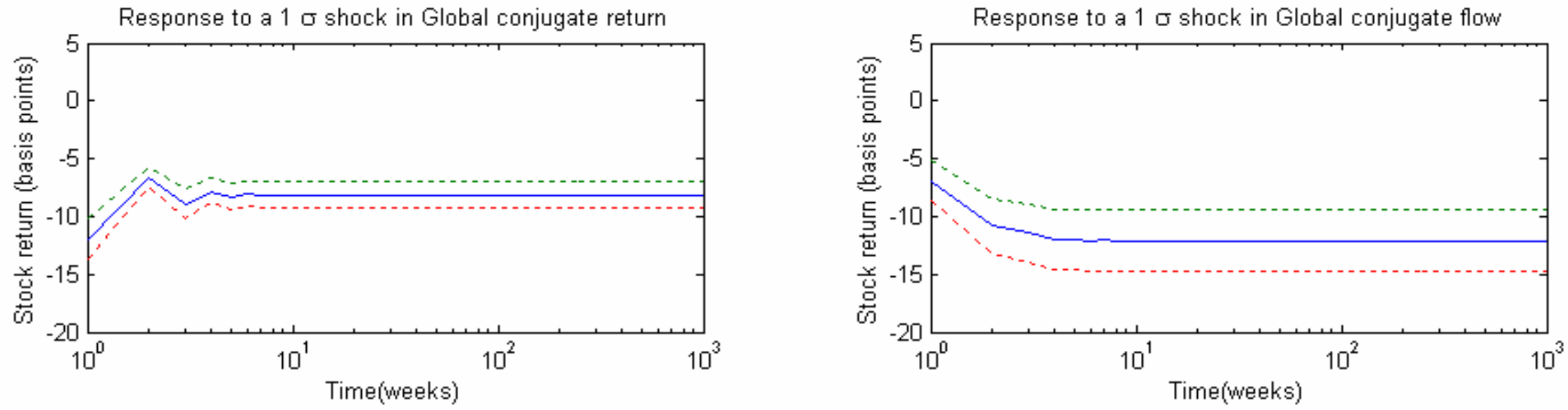

Figure 4b: Response of stock return to a one standard deviation shocks to conjugate variables. The sample period is from January 1995 to December 2001. The impulse responses are generated from a VAR estimated with the following state variables: Stock return, stock flow, stock ME, stock BM, stock ROE, size segment return, size segment flow, value/growth segment return, value/growth segment flow, sector return, sector flow, conjugate return, conjugate flow, global conjugate return, global conjugate flow. Dashed lines denote $+/-2$ standard error monte carlo bounds. 
Response to a 1 a shock in size segment return with no cash flow news Response to a 1 a shock in size segment flow with no cash flow news
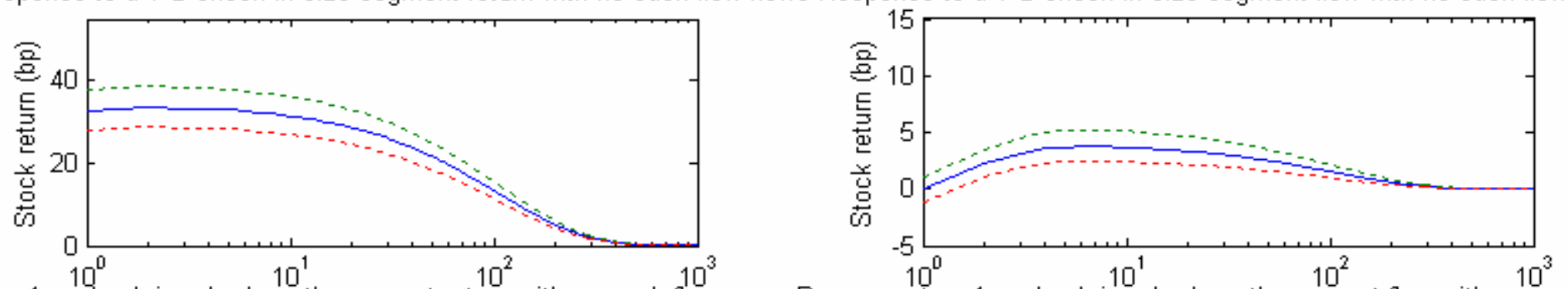

Response to a 1 $\square$ shock in value/growth segment return with no cash flow news Response to a 1 a shock in value/growth segment flow with no cash flow news
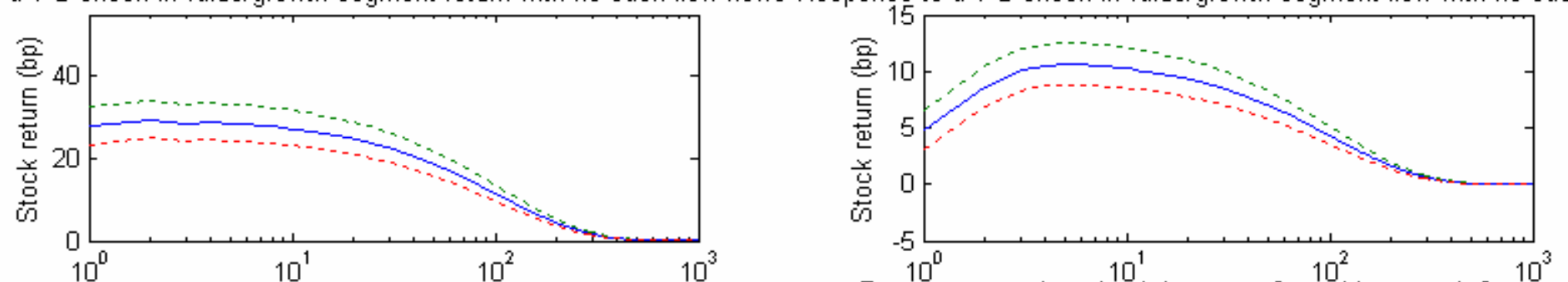

Response to a 1 o shock in sector return with no cash flow news
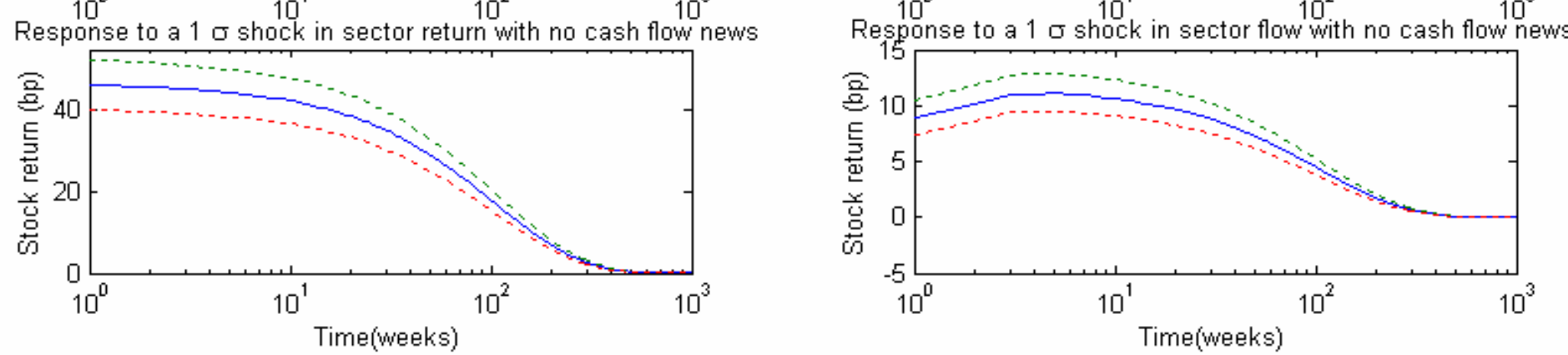

Figure 5a: Response of stock return to a one standard deviation shocks to own style variables with no cash flow news. The sample period is from January 1995 to December 2001. The 1 standard deviation shock in a variable is induced by setting the corresponding element of VAR error vector to the one standard deviation value. The other elements of the VAR error vector are set to their conditional expectations, conditional on the variable element being equal to its one standard deviation value and cash flow news equals zero. Dashed lines denote $+/-2$ standard error monte carlo bounds 
Response to a 1 o shock in conjugate return with no cash flow news

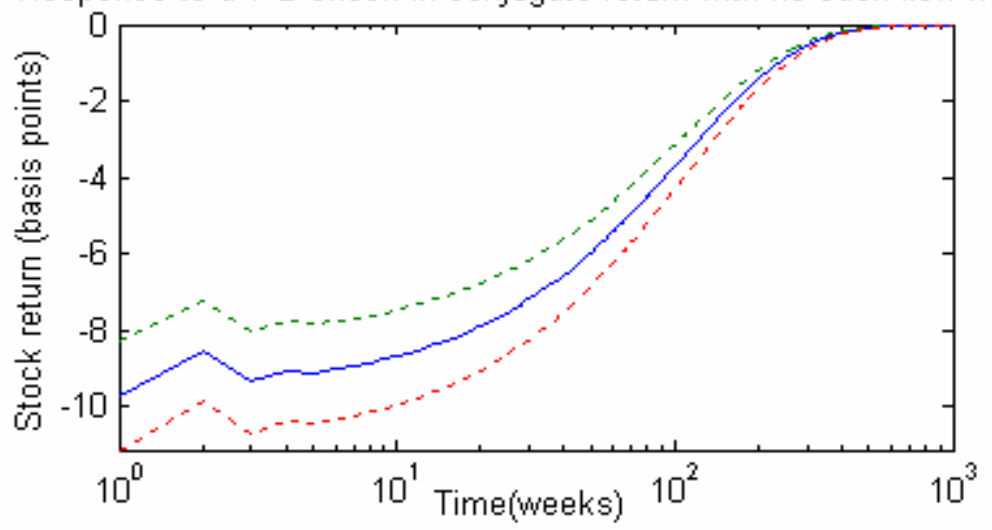

Response to a 1 o shock in conjugate flow with no cash flow news

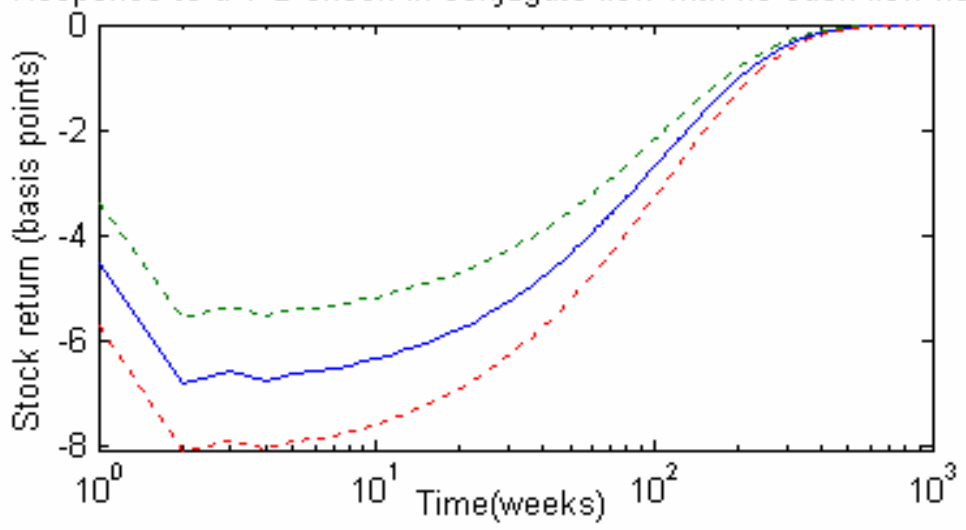

Response to a 1 व shock in Global conjugate return with no cash flow news Response to a 1 a shock in Global conjugate flow with no cash flow news
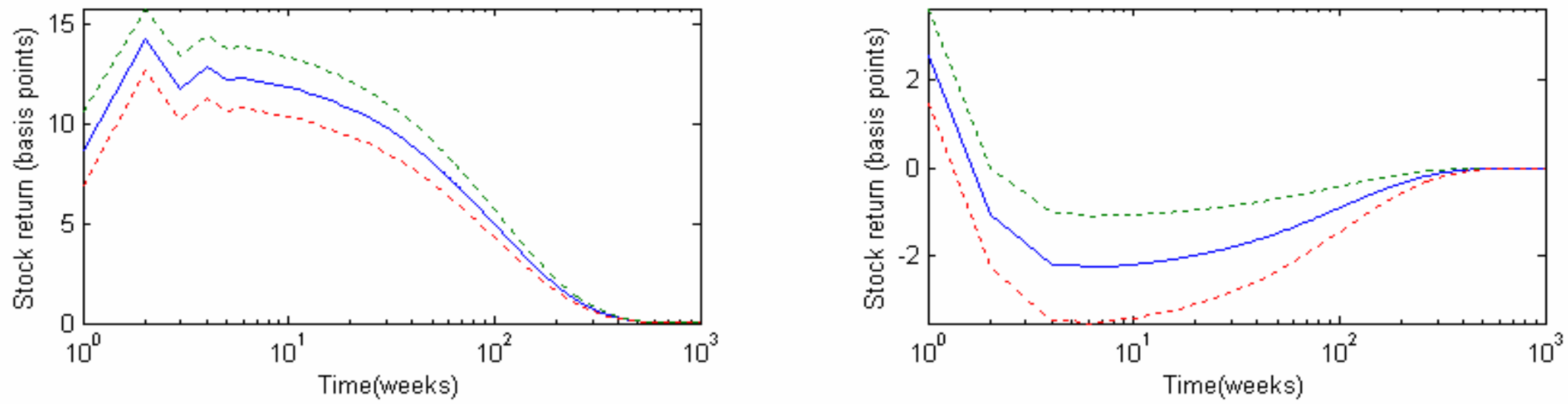

Figure 5b: Response of stock return to a one standard deviation shocks to conjugate variables with no cash flow news. The sample period is from January 1995 to December 2001. The 1 standard deviation shock in a variable is induced by setting the corresponding element of VAR error vector to the one standard deviation value. The other elements of the VAR error vector are set to their conditional expectations, conditional on the variable element being equal to its one standard deviation value and cash flow news equals zero. Dashed lines denote $+/-2$ standard error monte carlo bounds. 
Table I

\section{State Street Bank Daily US Flow Summary Statistics}

Summary flow statistics from State Street Bank's custodian flow database. The sample period is from 1995 to 2001 . The data are filtered to remove test and error transactions, and transactions which contain missing data fields. This flow database represents a substantial improvement over that used in Froot, O'Connell, and Seasholes (2001) as trades are recorded on a trade-date rather than on a settlement-date basis.

\begin{tabular}{cccc}
\hline Year & Number of US stocks with flows & Number of flow days & Aggregated absolute value of daily flows (billions) \\
\hline 1995 & 6,036 & 463,285 & 446 \\
1996 & 6,816 & 574,944 & 579 \\
1997 & 7,342 & 645,894 & 758 \\
1998 & 7,426 & 665,436 & 902 \\
1999 & 7,192 & 659,231 & 1,110 \\
2000 & 7,100 & 720,035 & 2,144 \\
2001 & 6,051 & 648,265 & 2,693 \\
\hline Total & 10,259 & $4,377,090$ & 8,632 \\
\hline
\end{tabular}




\section{Table II}

\section{Style Reallocation Intensities}

T-statistics against the median of a randomly drawn monte carlo reallocation intensity sample. The sample period is from January 1995 to December 2001. For each year and for each style (size, value/growth, cyclical/defensive, and sector) 1000 random monte carlo samples of styles are drawn so that their market capitalizations match those of the actual styles. The reallocation intensity statistics associated with these samples are calculated by looking at the stacked series of excess flows for all styles and for each year. Reallocation intensity is a measure of variation in flows in excess of expected flows based on market cap. The t-statistic is calculated as the difference in reallocation intensity between the actual style series and the 50th monte carlo percentile divided by the standard deviation of the monte carlo reallocations. The same process is also repeated over the entire sample. The standard cyclical/defensive measure is calculated as the correlation between the past stock returns with one year forward US gdp growth. Five years of stock returns are used. The forward looking cyclical/defensive measure is calculated as the correlation between stock returns in the 1995-2001 period with one year forward US gdp growth.

\begin{tabular}{|c|c|c|c|c|c|}
\hline year & size & value/growth & $\begin{array}{c}\text { style spectrum } \\
\text { cyclical/defensive } \\
\text { (standard) }\end{array}$ & $\begin{array}{l}\text { cyclical/defensive } \\
\text { (forward looking) }\end{array}$ & sector \\
\hline 1995 & 6.51 & 0.79 & 1.09 & 2.24 & 8.09 \\
\hline 1996 & 2.58 & 1.80 & 1.72 & 4.21 & 6.46 \\
\hline 1997 & 4.26 & 3.05 & 0.33 & 1.80 & 4.64 \\
\hline 1998 & 3.18 & 2.73 & 0.14 & 3.40 & 4.21 \\
\hline 1999 & 1.98 & 3.46 & 0.13 & 2.78 & 1.62 \\
\hline 2000 & 3.71 & 2.01 & 0.05 & 3.75 & 5.42 \\
\hline 2001 & 4.28 & 4.52 & 0.54 & 4.38 & 9.34 \\
\hline entire sample & 117.77 & 15.47 & 2.89 & 93.19 & 84.37 \\
\hline
\end{tabular}




\section{Table III}

\section{Flow correlations for size, value/growth, and cyclical/defensive segments}

The sample period is from January 1995 to December 2001. Excess flow correlations between various size (ME), value/growth (BM), and cyclical/defensive (CYC) segments Excess flow is flow into a segment in excess of its expected flow given its market cap. Portfolio distance is the difference in rank between portfolios, e.g., the distance between ME1 and ME5 is 4. Correlations are reported for pairs of portfolios with at least 1 extreme portfolios (e.g., ME1, ME10, BM1, etc.) The mean correlations between pairs of a certain distance for each distance are also reported. The t-statistics against that of 1000 monte carlo style segment samples are presented. The monte carlo style segment samples are drawn so that their market caps match those of the actual style segments.

Panel A: Flow correlations between size segments

\begin{tabular}{lcccccc}
\hline $\begin{array}{l}\text { Portfolio } \\
\text { distance }\end{array}$ & corr with ME1 & tstat & corr with ME10 & tstat & mean corr & mean tstat \\
\hline 1 & 0.26 & 3.56 & -0.10 & 0.07 & -0.04 & 0.66 \\
2 & 0.12 & 2.16 & -0.08 & 0.25 & -0.07 & 0.43 \\
3 & 0.06 & 1.59 & 0.00 & 1.06 & -0.05 & 0.56 \\
4 & -0.01 & 0.92 & -0.08 & 0.31 & -0.05 & 0.56 \\
5 & -0.08 & 0.24 & -0.18 & -0.69 & -0.16 & -0.53 \\
6 & -0.31 & -1.92 & -0.24 & -1.27 & -0.28 & -1.60 \\
7 & -0.09 & 0.23 & -0.15 & -0.41 & -0.19 & -0.82 \\
8 & -0.08 & 0.31 & -0.24 & -1.21 & -0.16 & -0.45 \\
9 & -0.44 & -3.19 & -0.44 & -3.19 & -0.44 & -3.19 \\
\hline Spearman's rho & $0.88^{* * *}$ & & $0.77^{* *}$ & & $0.83^{* * *}$ & \\
\hline
\end{tabular}

Panel B: Flow correlations between value/growth segments

\begin{tabular}{lcccccc}
$\begin{array}{l}\text { Portfolio } \\
\text { distance }\end{array}$ & corr with BM1 & tstat & corr with BM10 & tstat & mean corr & mean tstat \\
\hline 1 & 0.08 & 1.85 & 0.33 & 4.18 & 0.01 & 1.15 \\
2 & -0.21 & -0.92 & 0.06 & 1.62 & -0.09 & 0.18 \\
3 & -0.16 & -0.47 & -0.02 & 0.86 & -0.09 & 0.18 \\
4 & -0.25 & -1.38 & -0.18 & -0.71 & -0.14 & -0.29 \\
5 & -0.14 & -0.30 & 0.08 & 1.81 & -0.06 & 0.49 \\
6 & -0.27 & -1.52 & -0.15 & -0.43 & -0.20 & -0.83 \\
7 & -0.12 & -0.09 & -0.16 & -0.45 & -0.18 & -0.67 \\
8 & -0.34 & -2.17 & -0.23 & -1.18 & -0.28 & -1.67 \\
9 & -0.34 & -2.23 & -0.34 & -2.23 & -0.34 & -2.23 \\
\hline Spearman's rho & $0.63^{*}$ & & $0.82^{* * *}$ & & $0.88^{* * * *}$ & \\
\hline
\end{tabular}

Panel C: Flow correlations between cyclical/defensive segments

\begin{tabular}{lccccrr}
\hline $\begin{array}{l}\text { Portfolio } \\
\text { distance }\end{array}$ & corr with CYC1 & tstat & corr with CYC10 & tstat & mean corr & mean tstat \\
\hline 1 & -0.13 & -0.16 & 0.08 & 1.67 & -0.09 & 0.19 \\
2 & 0.03 & 1.29 & -0.05 & 0.58 & -0.08 & 0.27 \\
3 & -0.04 & 0.62 & -0.19 & -0.65 & -0.06 & 0.44 \\
4 & -0.01 & 0.88 & -0.22 & -0.92 & -0.14 & -0.32 \\
5 & -0.09 & 0.18 & -0.17 & -0.52 & -0.19 & -0.78 \\
6 & -0.21 & -0.87 & 0.05 & 1.47 & -0.08 & 0.30 \\
7 & -0.12 & -0.02 & -0.26 & -1.26 & -0.18 & -0.66 \\
8 & -0.10 & 0.11 & -0.09 & 0.21 & -0.10 & 0.13 \\
9 & -0.18 & -0.57 & -0.18 & -0.57 & -0.18 & -0.67 \\
\hline Spearman's rho & 0.48 & \multicolumn{7}{c}{0.5} & 0.5 \\
\hline
\end{tabular}

Note: $*$ Rho significant at the $10 \%$ level, $* *$ Rho significant at the $5 \%$ level *** Rho significant at the $1 \%$ level 


\section{Table IV}

\section{Principal Components Analysis of Style Flows}

The sample period is January 1995 to December 2001. Principal components analysis is performed on weekly excess flow into size segments (ME), weekly excess flow into value/growth segments (BM), and weekly excess flow into cyclical/defensive segments (CYC) separately. Next the segment flows are regressed individually on the top five principal components and the $\mathrm{R}$ squares from these regressions are recorded. The numbers presented are the $\mathrm{R}$ squares signed by the sign of the coefficient estimate on the principal components in the above-mentioned regressions. Significance is calculated relative to 1000 monte carlo style segment samples. These samples are drawn so that their market caps match those of the actual style segments.

Panel A: R squares from the regression of size segment flows on principal components * sign of slope estimate

\begin{tabular}{lccccc}
\hline & PC1 & PC2 & PC3 & PC4 & PC5 \\
\hline ME1 & $-0.401^{* *}$ & 0.023 & -0.013 & 0.015 & -0.026 \\
ME2 & $-0.247^{*}$ & 0.464 & -0.001 & -0.001 & -0.078 \\
ME3 & -0.09 & 0.365 & -0.031 & -0.079 & -0.046 \\
ME4 & -0.044 & -0.251 & -0.02 & $0.329^{*}$ & $-0.21^{*}$ \\
ME5 & -0.056 & -0.003 & $0.845^{* *}$ & 0.007 & 0.027 \\
ME6 & -0.007 & 0.141 & -0.146 & 0.055 & $0.451^{* *}$ \\
ME7 & 0.084 & -0.169 & 0.022 & -0.394 & -0.066 \\
ME8 & 0.017 & $-0.232^{*}$ & -0.078 & 0.077 & 0.108 \\
ME9 & 0.021 & -0.263 & -0.072 & -0.209 & 0.056 \\
ME10 & $0.804^{* *}$ & 0.026 & 0.008 & 0.005 & -0.001 \\
\hline \% of cross-section explained & & & & & \\
by principal component & 23.057 & $17.658^{*}$ & 13.911 & 10.858 & 9.563 \\
\hline
\end{tabular}

Panel B: R squares from the regression of value/growth segment flows on principal components * sign of slope estimate

\begin{tabular}{lccccc}
\hline & PC1 & PC2 & PC3 & PC4 & PC5 \\
\hline BM1 & $-0.882^{* *}$ & 0.004 & -0.01 & 0 & 0 \\
BM2 & -0.154 & $-0.401^{* *}$ & $0.39^{* *}$ & 0.001 & -0.006 \\
BM3 & 0.032 & -0.008 & 0 & $-0.624^{* *}$ & $0.205^{*}$ \\
BM4 & 0.044 & 0.098 & -0.159 & -0.032 & $-0.332^{*}$ \\
BM5 & 0.076 & $-0.386^{* *}$ & $-0.364^{*}$ & 0.06 & 0.019 \\
BM6 & 0.011 & 0.006 & -0.003 & -0.126 & -0.069 \\
BM7 & 0.068 & -0.033 & -0.006 & -0.003 & $-0.30^{* *}$ \\
BM8 & 0.025 & $0.538^{* *}$ & 0.123 & 0.036 & 0.004 \\
BM9 & 0.207 & $0.216^{* *}$ & 0.064 & $0.11^{* *}$ & 0.098 \\
BM10 & 0.231 & 0.023 & 0 & 0.341 & 0.164 \\
\hline \% of cross-section explained & & & & & \\
by principal component & $27.542^{* *}$ & 17.562 & 12.382 & 10.759 & 8.955 \\
\hline
\end{tabular}


Table IV (continued)

Panel C: mean R squares from the regression of random ME / BM segment flows on principal components $*$ sign of slope estimate (1000 monte carlo trials)

\begin{tabular}{lccccc}
\hline & PC1 & PC2 & PC3 & PC4 & PC5 \\
\hline RAND1 & -0.012 & -0.009 & 0.016 & -0.005 & 0.010 \\
RAND2 & 0.008 & 0.005 & -0.012 & 0.006 & -0.003 \\
RAND3 & -0.012 & -0.006 & -0.002 & 0.019 & -0.005 \\
RAND4 & -0.004 & 0.009 & 0.012 & 0.004 & -0.005 \\
RAND5 & 0.007 & 0.012 & -0.004 & 0.004 & 0.001 \\
RAND6 & 0.005 & 0.006 & 0.001 & -0.003 & 0.003 \\
RAND7 & -0.021 & 0.012 & -0.013 & 0.003 & 0.000 \\
RAND8 & -0.006 & 0.016 & -0.018 & 0.002 & -0.003 \\
RAND9 & -0.003 & -0.023 & 0.002 & -0.015 & -0.004 \\
RAND10 & 0.002 & 0.002 & 0.002 & -0.007 & 0.005 \\
\hline \% of cross-section explained & & & & & \\
by principal component & 20.461 & 16.042 & 13.337 & 11.458 & 10.008 \\
\hline
\end{tabular}

Panel D: R squares from the regression of cyclical/defensive segment flows on principal components * sign of slope estimate

\begin{tabular}{lccccc}
\hline & PC1 & PC2 & PC3 & PC4 & PC5 \\
\hline CYC1 & -0.047 & 0.011 & -0.06 & 0.044 & 0 \\
CYC2 & 0.012 & 0.122 & $-0.257^{*}$ & 0.001 & -0.048 \\
CYC3 & $-0.367^{*}$ & -0.001 & -0.007 & 0.372 & 0.125 \\
CYC4 & $0.545^{* *}$ & 0.029 & -0.19 & 0.02 & 0.029 \\
CYC5 & -0.12 & 0.001 & -0.005 & -0.034 & $-0.558^{* *}$ \\
CYC6 & -0.073 & -0.197 & -0.074 & $-0.515^{* *}$ & 0.108 \\
CYC7 & 0.217 & $-0.564^{* *}$ & 0.046 & 0.038 & -0.001 \\
CYC8 & -0.013 & 0 & 0.144 & -0.006 & -0.157 \\
CYC9 & -0.091 & 0.014 & $0.395^{* *}$ & 0.002 & 0.013 \\
CYC10 & 0.125 & $0.37^{* *}$ & 0.235 & -0.068 & 0.067 \\
\hline \% of cross-section explained & 17.899 & 15.715 & 13.469 & 12.438 & 10.252 \\
by principal component & \multicolumn{7}{c}{}
\end{tabular}

Panel E: mean R squares from the regression of random CYC segment flows on principal components * sign of slope estimate (1000 monte carlo trials)

\begin{tabular}{lccccc}
\hline & PC1 & PC2 & PC3 & PC4 & PC5 \\
\hline RAND1 & -0.012 & -0.009 & 0.016 & -0.005 & 0.010 \\
RAND2 & 0.008 & 0.005 & -0.012 & 0.006 & -0.003 \\
RAND3 & -0.012 & -0.006 & -0.002 & 0.019 & -0.005 \\
RAND4 & -0.004 & 0.009 & 0.012 & 0.004 & -0.005 \\
RAND5 & 0.007 & 0.012 & -0.004 & 0.004 & 0.001 \\
RAND6 & 0.005 & 0.006 & 0.001 & -0.003 & 0.003 \\
RAND7 & -0.021 & 0.012 & -0.013 & 0.003 & 0.000 \\
RAND8 & -0.006 & 0.016 & -0.018 & 0.002 & -0.003 \\
RAND9 & -0.003 & -0.023 & 0.002 & -0.015 & -0.004 \\
RAND10 & 0.002 & 0.002 & 0.002 & -0.007 & 0.005 \\
\hline \% of cross-section explained & & & & & \\
by principal component & 20.461 & 16.042 & 13.337 & 11.458 & 10.008 \\
\hline
\end{tabular}

Note: * Significant at the $10 \%$ level, ** Significant at the $5 \%$ level 
Table V

OLS Firm Fixed-effects Panel Regression of Individual Stock Returns

Sample period is from January 1995 to December 2001 and consists of 291,455 firm-days. The dependent variable is individual stock return. The independent variables are weekly lags of stock returns and flows, size segment returns and flows, value/growth segment returns and flows sector flow, sector segment returns and flows, conjugate return and flow, global conjugate return and flow, as well as stock BM, ME, and ROE. Flows are net inflows normalized by market equity. Returns are excess of the US market. All segment flows and returns are value-weighted. Conjugate flow is the value-weighted flow of all the stocks not in the size segment, value/growth segment or sector of the stock. Global conjugate flow is the value-weighted flow of all countries excluding the United States. The conjugate return variables are defined analogously. The t-statistics in parentheses are from standard errors corrected for cross-sectional heteroskedasticity (Beck and Katz, 1995).

\begin{tabular}{|c|c|c|c|c|}
\hline $\begin{array}{l}\text { Independent variables } \\
(\text { Coefficient } * \text { std dev) } \\
\text { Units }=\text { basis pt of return }\end{array}$ & $\begin{array}{c}\text { Model } 1 \\
\text { lag }=1 \text { week }\end{array}$ & lag $=1$ week & $\begin{array}{c}\text { Model } 2 \\
\text { lag }=2-4 \text { week }\end{array}$ & lag $=5-12$ week \\
\hline Size segment return & $\begin{array}{c}4.1 \\
(3.23)\end{array}$ & $\begin{array}{c}0.5 \\
(0.4)\end{array}$ & $\begin{array}{c}6.8 \\
(5.13)\end{array}$ & $\begin{array}{c}4.4 \\
(3.1)\end{array}$ \\
\hline Size segment flow & $\begin{array}{c}5.25 \\
(4.22)\end{array}$ & $\begin{array}{l}2.95 \\
(2.19)\end{array}$ & $\begin{array}{c}-1.4 \\
(-0.89)\end{array}$ & $\begin{array}{c}11.6 \\
(7.24)\end{array}$ \\
\hline Value/growth segment retur & $\begin{array}{c}3.95 \\
(2.96)\end{array}$ & $\begin{array}{c}2.35 \\
(1.75)\end{array}$ & $\begin{array}{c}13.2 \\
(9.24)\end{array}$ & $\begin{array}{c}4.8 \\
(3.06)\end{array}$ \\
\hline Value/growth segment flow & $\begin{array}{c}15.4 \\
(11.83)\end{array}$ & $\begin{array}{c}14.7 \\
(10.82)\end{array}$ & $\begin{array}{l}-10.6 \\
(-6.72)\end{array}$ & $\begin{array}{c}0.5 \\
(0.32)\end{array}$ \\
\hline Sector segment return & $\begin{array}{c}2 \\
(1.59)\end{array}$ & $\begin{array}{c}0.8 \\
(0.63)\end{array}$ & $\begin{array}{c}7.75 \\
(6.13)\end{array}$ & $\begin{array}{c}-6.95 \\
(-5.48)\end{array}$ \\
\hline Sector segment flow & $\begin{array}{c}4.65 \\
(3.77)\end{array}$ & $\begin{array}{l}3.15 \\
(2.46)\end{array}$ & $\begin{array}{c}7.75 \\
(5.46)\end{array}$ & $\begin{array}{l}-1.25 \\
(-0.89)\end{array}$ \\
\hline Conjugate return & $\begin{array}{l}-2.85 \\
(-2.34)\end{array}$ & $\begin{array}{c}-5.5 \\
(-4.41)\end{array}$ & $\begin{array}{l}12.95 \\
(9.92)\end{array}$ & $\begin{array}{l}-12.25 \\
(-9.56)\end{array}$ \\
\hline Conjugate flow & $\begin{array}{c}-14.15 \\
(-11.54)\end{array}$ & $\begin{array}{c}-14.55 \\
(-11.34)\end{array}$ & $\begin{array}{l}-3.95 \\
(-2.75)\end{array}$ & $\begin{array}{c}10.7 \\
(7.37)\end{array}$ \\
\hline Global conjugate return & $\begin{array}{l}-14.8 \\
(-12.6)\end{array}$ & $\begin{array}{c}-16.95 \\
(-13.87)\end{array}$ & $\begin{array}{c}-15.15 \\
(-12.32)\end{array}$ & $\begin{array}{l}-7.35 \\
(-6.24)\end{array}$ \\
\hline Global conjugate flow & $\begin{array}{l}-4.85 \\
(-4.29)\end{array}$ & $\begin{array}{l}-5.75 \\
(-4.53)\end{array}$ & $\begin{array}{c}3.55 \\
(2.47)\end{array}$ & $\begin{array}{c}-6.3 \\
(-4.71)\end{array}$ \\
\hline Stock BM & $\begin{array}{c}20.5 \\
(13.74)\end{array}$ & $\begin{array}{c}20.4 \\
(13.43)\end{array}$ & & \\
\hline Stock ME & $\begin{array}{c}-5.7 \\
(-5.93)\end{array}$ & $\begin{array}{l}-6.15 \\
(-6.34)\end{array}$ & & \\
\hline Stock ROE & $\begin{array}{c}1.4 \\
(1.18)\end{array}$ & $\begin{array}{c}1.6 \\
(1.34)\end{array}$ & & \\
\hline R squared & 0.006 & & 0.012 & \\
\hline
\end{tabular}

